\title{
Interactive Malaria Education Intervention and its Effect on Community Participant Knowledge: The Malaria Awareness Program (MAP) in Vhembe District, Limpopo, South Africa
}

Sarah N. Cox ${ }^{1, *}$, Kathryn E. Guidera ${ }^{2}$, Molly J. Simon ${ }^{2}$, Bareng Aletta Sanny Nonyane ${ }^{1}$, William Brieger $^{1}$, Maria Susanna Bornman ${ }^{3}$, and Philippus Stephanus Kruger ${ }^{4}$

${ }^{1}$ Johns Hopkins University Bloomberg School of Public Health, Baltimore, MD, USA

${ }^{2}$ One Sun Health Inc., New York, USA \& Mpumalanga, ZA

${ }^{3}$ Faculty of Health Sciences, University of Pretoria, Pretoria, Gauteng, South Africa

${ }^{4}$ Limpopo Department of Health, Polokwane, Limpopo, South Africa

* Corresponding Author:

Sarah Cox, Johns Hopkins University Bloomberg School of Public Health, 615 N Wolfe St, Baltimore, MD 21205-2103, USA.

Email: scox23@jhu.edu

\section{Abstract}

Malaria is preventable and treatable, yet remains the most prevalent parasitic endemic disease in Africa. This paper analyzes prospective observational data from the Malaria Awareness Program (MAP), an interactive malaria education initiative led by homebased care ( $\mathrm{HBC})$ workers to improve participant knowledge of malaria as a precursor to increased uptake of malaria control interventions in the Vhembe District, Limpopo, South Africa. Between $2012-2016,1330$ individuals participated in MAP. MAP's effectiveness was measured through pre- and post-participation surveys assessing knowledge in malaria transmission, symptoms, prevention and treatment. The primary analysis assessed differences in knowledge between individuals who completed MAP $(n=499)$ and individuals who did not complete MAP ( $n=399)$. The adjusted odds of correct malaria knowledge score 
versus partially correct and/or incorrect score among MAP completers was 3.3 and 2.8 times greater for transmission and prevention, respectively ( $p$-values $<0.001)$. A sub-analysis assessed knowledge improvement among participants who completed both pre- and postMAP intervention surveys $(n=266)$. There was a $21.4 \%$ and $10.5 \%$ increase in the proportion of participants who cited correct malaria transmission and prevention methods, respectively. Future research should assess behavioral changes toward malaria prevention and treatment as a result of an intervention, and examine incidence changes in the region.

Keywords: malaria, community education, home-based care workers, knowledge, South Africa, community health workers

\section{Introduction}

Malaria is an acute febrile illness caused by parasitic infection spread through the bite of an infected female Anopheles mosquito. In 2016, nearly half of the world's population was at risk of malaria, with 212 million cases and 429,000 deaths globally. ${ }^{1}$ Currently, Sub-Saharan Africa's malaria burden is disproportionally high, with $90 \%$ of all malaria cases and $92 \%$ of deaths occurring in this region in $2015 .{ }^{1}$ South Africa is one of the frontline malaria elimination countries in the Southern African Development Community (SADC) and thus plays a pivotal role in assisting neighboring countries in their continued efforts. $^{2}$

An estimated $10 \%$ of the South African population lives at risk of contracting malaria within three malaria-endemic provinces: Limpopo, Mpumalanga, and KwaZulu-Natal., Although South Africa has achieved and exceeded the UN Millennium Development Goals for malaria control, Limpopo Province recorded the lowest reduction in malaria cases 
compared to other malaria endemic provinces within the country between 2000 and $2010 .^{3}$ From 2013 to 2014, Limpopo's reported cases of malaria increased from approximately 2,400 to 5,700 cases, of which the majority of cases were acquired locally within the Limpopo Province, as opposed to outside of the region. ${ }^{5}$ The Vhembe district, within the Limpopo Province, accounts for over $60 \%$ of all malaria cases reported annually, with an incidence of 2.4 per 1,000 population at risk by $2014 .^{5}$

South Africa's Malaria Control Programme currently employs five key strategies for malaria control, including surveillance, case management, cross-border malaria initiatives, vector control, and health promotion. ${ }^{3}$ The primary malaria vector control strategy is the universal coverage of Indoor Residual Spraying (IRS) of homes with using mostly pyrethroids and limited Dichlorodiphenyltrichloroethane (DDT) insecticide, which is conducted annually in all high-risk malaria zones before the rainy, transmission season (August - March). Between 2010 - 2014 IRS coverage in Limpopo was estimated between $85-90 \%{ }^{5}$ The Midterm Review of South Africa's Malaria Elimination Strategic Plan for 2012 - 2018 recommended a strengthening of IRS management and monitoring, as well as an increase in "funding and staff for health education on malaria elimination through health promotion." Health promotion is an essential tool to educate communities about malaria and ensure compliance with IRS campaigns.

Health promotion is highlighted as a key objective of South Africa's Malaria Elimination Strategy, which aims to ensure that by $2018,100 \%$ of the population has adequate malaria knowledge, attitudes and practices. ${ }^{7}$ Knowledge and awareness is one of four key indicators included in Roll Back Malaria's Behavior Change Communication (BCC) intervention strategy to initiate, promote, and sustain desired behavior change. ${ }^{8,9}$ Highquality $\mathrm{BCC}$ integration and its evaluation are essential for malaria control programs to 
improve malaria prevention and treatment. ${ }^{10}$ As South Africa moves towards malaria elimination, investment in community health promotion and BCC, as well as evaluative research, are crucial to increasing malaria understanding and compliance with prevention and treatment measures.

One Sun Health (OSH) is a 501(c)3 non-profit organization and South African nonprofit company that aims to promote sustainable, locally driven solutions to public health challenges through community health education and social entrepreneurship initiatives in South Africa. ${ }^{11}$ The Malaria Awareness Program (MAP) is OSH's flagship initiative that facilitates the training of home-based care (HBC) workers to create partnerships and lead education sessions with community members in order to improve knowledge surrounding malaria. HBC workers partner with local clinics and are known and respected by the community. Thus, they are the ideal advocates to develop, inform, and lead MAP in order to promote long-term sustainability. This article analyzes prospective observational data from the MAP, an interactive malaria education program led by local HBC workers that aims to improve malaria knowledge of participants in the Vhembe District, Limpopo, South Africa (Figure 1 a, b, Supplemental Materials).

\section{Methods}

From 2012 to 2016, MAP education sessions were conducted in HaMakuya and Masisi sub-districts, located in the Vhembe District, Limpopo Province, South Africa. Over five years, 19 villages with a combined population of approximately 12,398 were selected to participate in MAP by representatives of the Makuya Clinic and the Malaria Control Programme based on their high malaria prevalence and risk (Table 1). The MAP study design and protocol, as well as the process for program evaluation are described below. 
Table 1.

Villages participating in Malaria Awareness Program (MAP) workshops from 2012 2016, South Africa

\begin{tabular}{|c|c|c|c|c|}
\hline \multicolumn{5}{|c|}{ MAP Workshops $2012-2016$} \\
\hline Region & Village & Year of MAP & $\begin{array}{c}\text { Participants } \\
\text { included in } \\
\text { primary } \\
\text { analysis }\end{array}$ & $\begin{array}{c}\text { Overall } \\
\text { Village } \\
\text { Population }^{\text {a }}\end{array}$ \\
\hline \multirow{15}{*}{ HaMakuya } & Dohta & 2012 & 60 & 179 \\
\hline & Domboni & 2013,2016 & 15 & 247 \\
\hline & Fandani & 2014,2016 & 22 & 170 \\
\hline & Gondeni & 2014,2015 & 34 & 5391 \\
\hline & Guyuni & 2014,2016 & 80 & 906 \\
\hline & Khavhambe & 2013,2015 & 56 & 355 \\
\hline & Lamvi & 2012 & 28 & 712 \\
\hline & Madamuni & 2013 & 58 & Not available \\
\hline & Maholoni & 2013 & 25 & 276 \\
\hline & Maludzawela & 2013 & 110 & 132 \\
\hline & Muhotoni & 2012 & 41 & 69 \\
\hline & Mukoma & 2012,2016 & 30 & 388 \\
\hline & Musunda & 2012,2015 & 86 & 319 \\
\hline & Sanari & 2012 & 50 & 976 \\
\hline & Tshambuka & 2013 & 53 & 295 \\
\hline \multirow{4}{*}{ Masisi } & Bende Mutale & 2015,2016 & 35 & 781 \\
\hline & Mutale B & 2015 & 55 & 728 \\
\hline & Nkwotsi & 2015,2016 & 20 & 137 \\
\hline & Tshikuyu & 2015 & 40 & 337 \\
\hline
\end{tabular}

${ }^{a}$ Note: Population estimates are derived from Census 2011 STATS SA

\section{Study Design and Protocol}

MAP was structured as a quasi-experimental, before and after study consisting of a three- or four-week intervention in the selected high-risk malaria villages. Community members from each selected village participated in one workshop per week, held for two to three hours on a weekday morning in their respective village. MAP participants were recruited through a volunteer sample, where village leaders were notified of MAP and asked to advertise workshops through word-of-mouth and direct communication. MAP workshops 
were typically held outside each village leader's home, a traditional location for community forums that encourages participation from all.

Any resident in a selected village who attended a workshop was screened for eligibility. Individuals over 18 years of age with the ability to consent were eligible to participate in MAP. Consent and photo release forms were read orally to the group at the start of each workshop. Those who wished to participate signed (or had a witness sign) a written consent form. Those who wished to have their photos taken signed (or had a witness sign) a written photo release form. HBC workers collected all consent and release forms. Those who did not participate in the consent and/or release process were able to participate in the education sessions; however, their data and/or photos were not collected. All participants signed an attendance sheet at each workshop.

Written survey questions were administered individually at the beginning of the first (week one) and last (week three or four) MAP workshops to assess the program's impact on malaria-related knowledge among participants. Instruction on completing surveys were provided verbally by HBC workers and printed on the survey form. Surveys were selfadministered by all participants who could read and write. Those who could not read or write were given the survey verbally by a $\mathrm{HBC}$ worker who recorded written answers for the participant. Individuals who attended two to four MAP workshops and received the education intervention were compared with participants who attended only one MAP workshop and received no malaria education intervention.

MAP used the community as a resource by soliciting local input and knowledge, while working closely with government, nonprofit, and healthcare organizations in order to target misconceptions about malaria. All program and educational materials were developed in English and Tshivenda, the local language, and designed in coordination with 
the Limpopo Department of Health's Malaria Control Division to ensure alignment with

South Africa's national strategic plan to combat malaria (Table 2; Figure 2, Supplemental

Materials).

Table 2.

MAP Study Curriculum Components, South Africa

\begin{tabular}{|c|c|}
\hline Component & Description \\
\hline Transmission & $\begin{array}{l}\text { Curricula focuses on the transmission process, the history and seasonality of the disease, } \\
\text { and those who are most susceptible to transmission of the disease (e.g. immigrants } \\
\text { moving into endemic areas) as well as impact from the disease (e.g. pregnant women). } \\
\text { Content is supplemented by visual diagram demonstrating the transmission cycle } \\
\text { between a mosquito and human. }\end{array}$ \\
\hline Symptoms & $\begin{array}{l}\text { Curricula focuses on recognition of key symptoms of malaria, such as fever, headache, } \\
\text { and vomiting. Severe symptoms are also covered. Content is supplemented by interactive } \\
\text { human body activity in which participants write malaria symptoms on a post-it note and } \\
\text { place it on a human body diagram. Participants also sing the "MAP Anthem" after each } \\
\text { workshop, which describes a series of malaria symptoms. }\end{array}$ \\
\hline Prevention & $\begin{array}{l}\text { Curricula focuses on behavioral prevention techniques such as allowing Indoor Residual } \\
\text { Spraying (IRS) performed by Malaria Control teams, remaining indoors with windows } \\
\text { closed and wearing long sleeves in the evening, burning mosquito coils, using repellant } \\
\text { creams, and sleeping under mosquito nets. Content is supplemented by a malaria drama } \\
\text { in which HBCWs present the life story of one individual who follows preventative } \\
\text { measures and that of an individual who does not. In many cases, this drama is replicated } \\
\text { by community participants in the final MAP workshop. }\end{array}$ \\
\hline Treatment & $\begin{array}{l}\text { Curricula focuses on effective treatment seeking behavior, including visiting a clinic for a } \\
\text { diagnostic test immediately upon experiencing symptoms. It also includes a description } \\
\text { of medication used to treat malaria-positive individuals and best practices with regard to } \\
\text { adherence and sharing of any medication. Key medical contacts are provided and are } \\
\text { captured in a written and graphic pamphlet that can be taken home and shared. }\end{array}$ \\
\hline
\end{tabular}

\section{MAP Leadership and Training}

MAP workshops were led by a group of local HBC workers and district-level Malaria

Control representatives in an effort to work within pre-existing structures, increasing

likelihood of program sustainability. HBC workers are defined as both formal and informal

caregivers in the home who promote physical, psychosocial, palliative, and spiritual health,

helping individuals and families achieve the best possible quality of life. ${ }^{12}$ In HaMakuya and

Masisi, there are five HBC organizations, which consist of approximately sixty individuals in

total, the majority of whom are female. Each HBC organization works under direction from 
their local clinic and is responsible for health promotion activities and campaigns as well as home visits to specific patients.

Six HBC workers with leadership skills, as identified by their HBC Managers, were nominated to work with $\mathrm{OSH}$, Malaria Control, and the head nurse from the Makuya Clinic to develop the initial MAP curriculum and interactive activities. These HBC workers then led annual two day trainings for HBC workers from all villages before initiating and leading MAP workshops. Training was completed in Tshivenda and involved review of MAP curriculum through both written and verbal educational content. As part of the training, $\mathrm{HBC}$ workers practiced interactive teaching techniques to be incorporated into the community workshops. Training ended with rehearsals of each workshop, in which $\mathrm{HBC}$ workers role-played community and facilitator positions to provide feedback and ensure cohesion and consistency. Quality and consistency of training sessions were ensured through a structured curriculum that was delivered by MAP Coordinators with oversight from OSH leaders, both in person and through virtual reporting and correspondence. To mitigate challenges related to potential limited literacy of some HBC workers, training content was delivered through verbal instruction in full in addition to written material. In 2016, OSH began giving pre- and post- knowledge surveys to $\mathrm{HBC}$ workers in order to confirm an understanding of malaria before beginning community workshops.

After completion of training, HBC workers began in-village education sessions under the direction of OSH and the local Malaria Control representatives. The number of HBC workers and Malaria Control representatives at each workshop depended on their availability and convenience, as well as size and location of the participating village. At least three HBC workers were required to be present at each workshop. There was no minimum number of Malaria Control representatives required to be present. 
In addition to HBC workers, each year two or three volunteer MAP Coordinators assisted with facilitation of MAP. These coordinators were recruited through OSH and consisted of students from the University of Pretoria and various universities in the United States seeking health fieldwork experience. Responsibilities of MAP Coordinators included logistical support (document printing, data translation and entry), observing MAP workshops in each village for quality and consistency, as well as planning an annual celebration for all HBC workers and local stakeholders after each MAP implementation.

\section{MAP Education Curriculum}

The MAP curriculum was developed during a two-day retreat hosted by OSH in partnership with a select group of six HBC workers, two local Malaria Control representatives, and the head nurse from the Makuya Clinic. The malaria education materials were based on global, national, and local guidelines, and were later approved by the Limpopo Department of Health. The curriculum focused on interactive activities and discussions around malaria transmission, symptoms, prevention, and treatment (Table 2). These four learning objectives on malaria were taught by HBC workers and measured through pre- and post-surveys.

The first week of MAP assessed both individual and community knowledge of malaria, as well as provided a basic overview of the disease. Through the administration of individual pre-surveys, small-group focus questions, and a full-group activity on participants' initial associations with malaria, $\mathrm{HBC}$ workers collected data on basic demographics and assessed malaria knowledge to tailor the program. Notably, $\mathrm{HBC}$ workers developed a song to emphasize teaching of common malaria symptoms, entitled "Malaria Anthem." At the end of each MAP workshop, HBC workers and participants sang the Malaria Anthem. 
The second and third weeks of MAP focused on interactive community education centered on the four identified malaria knowledge topics (Table 2). An example workshop activity was the human body symptom activity. To review symptoms specific to malaria, participants were given a poster with the outline of a human body. HBC workers distributed post-it notes and asked the community to write symptoms that they associated with malaria and place them on the human body poster where the symptom occurred. These symptoms were then presented and discussed as a group. $\mathrm{HBC}$ workers addressed misconceptions as well as pointed out additional symptoms if any were missing. Finally, community participants were asked to discuss how they would change their human body symptoms given new information.

The final week of MAP workshops involved individual post-surveys, review of important information, and presentation of certificates of completion. At the end of each weekly workshop, pamphlets in Tshivenda were distributed to MAP participants to provide an overview and illustrations of each focus area, in addition to contact information of local clinics and Emergency Medical Services (EMS). MAP strived to maintain a curriculum run entirely by $\mathrm{HBC}$ workers in Tshivenda that was professional, interactive, straightforward, and replicable. A detailed breakdown of the MAP curriculum can be found in Figure 2, Supplemental Materials.

\section{Study Evaluation}

The MAP intervention measured malaria knowledge through surveys (Figures $3 a, 3 b$, Supplemental Materials), which were created in partnership with the University of Pretoria, clinic personnel at Makuya Clinic, and Limpopo Province Department of Health representatives. Pre- and post-surveys were administered to all participants who met eligibility criteria (at least 18 years of age and able to provide consent). Surveys took 
approximately 10-15 minutes to complete per participant and included the same 10 openended questions to prevent response leading. The post-survey included seven additional questions focused on perceived effectiveness of MAP and program satisfaction.

\section{Survey Development and Knowledge Construct}

Knowledge on transmission and prevention were measured based on an ordinal knowledge score, quantified from responses to targeted survey questions. Classification of participant responses was based on previously published studies that assessed malaria knowledge in various international community settings (Table 9, Supplemental Materials). Based on the literature, participant responses to questions of transmission and prevention were labeled as either "incorrect, no understanding," "partially correct, some understanding," or "correct, complete understanding" (Figures 4a and 4b, Supplemental Materials).

For participant knowledge of symptoms and treatment, understanding was measured based on number of correct responses. Overall participant enjoyment of MAP and suggestions for the future were recorded and analyzed using a Likert scale of one to five.

Predictor variables included demographic data tracked by unique participant ID. These variables were gender [male, female], age [18 - <30, $30-<40,40+$ years], number of years of education completed [grade $0-8,>8-<12,12+$, where $12+$ indicates high school graduation or some education at the university level], and year of MAP participation [2012, $2013,2014,2015,2016]$. The number of MAP meetings attended by each participant was the main predictor variable and coded as 1 if the participant had received the MAP intervention (attended two to four MAP meetings), and 0 if only one meeting was attended. 


\section{Data Collection}

Each meeting began with the consent and release process, and was followed by participants signing an attendance sheet collected by HBC workers. All participants were informed about the study and their right to opt out at any time.

At the first and final workshops in each village, $\mathrm{HBC}$ workers distributed individual paper surveys directly after the consent and release process, prior to reviewing any educational material. After surveys were completed, HBC workers or MAP Coordinators completed quality checks to ensure data was complete and accurate, and readministered questions to individuals as needed if there were gaps or errors in the completion of the survey.

\section{Data Analysis}

Data were collected in Tshivenda, translated into English by a local translator, and entered into Microsoft Excel in full. The primary analysis assessed differences in knowledge between those who completed the MAP intervention (defined by assessment of knowledge after attending two to four MAP workshops) and those who did not complete the MAP intervention (defined by assessment of knowledge prior to attending any MAP workshop). A subanalysis on knowledge improvement among MAP participants who completed both preand post-MAP intervention surveys is also presented. All analyses were performed using Stata $13 .^{13}$

Baseline characteristics of the participants in the two groups from the primary data set (MAP versus no MAP) were compared through chi-squared tests using a threshold $p=0.05$ as a cut-off for significance. Mean age and education level completed were calculated, as well as their corresponding ranges. The distribution of survey responses between MAP participation considered four main knowledge categories: transmission, 
symptoms, prevention, and treatment. Chi-squared tests were used to test for the independence between these knowledge scores distribution and MAP group.

Knowledge of transmission and prevention of malaria was measured based on an ordinal knowledge score. A multiple ordinal logistic regression model was fitted for the knowledge score with MAP vs. no MAP as a main predictor, adjusting for education, age, gender, and year. The Brant test was used to assess the assumption of proportional odds for the multiple ordinal logistic regression.

Summary data from the program evaluation and anecdotal quotes from focus group discussions were also presented, indicating the community's enjoyment of MAP and willingness to participate in the future. The data from four program evaluation questions were analyzed based on the mean and proportion of participant's Likert scale scores (1: very little/unlikely; 5: very likely/a lot) (Figure 3a, 3b, Supplemental Materials).

This study investigated collinearity among variables, as well as interaction between MAP and predictor variables (education, age). Multiple imputation was conducted for education level completed after assessing changes in effect size with and without the imputation.

\section{Ethical Considerations}

Ethical clearance for research through Institutional Review Board (IRB) was secured from Duke University and Washington University in Saint Louis before implementation of this intervention. The program was also approved by the University of Pretoria IRB, the Limpopo Department of Health, Vhembe District Department of Health, Makuya Clinic, HaMakuya Inter Sectoral Committee, and the Makuya Tribal Council. 


\section{Results and Analysis}

From 2012 - 2016, sixty HBC workers were trained under the facilitation of MAP and Malaria Control representatives from the Limpopo Department of Health. These HBC workers in turn led a total of 28 MAP interventions in 19 villages, with each intervention including three or four education sessions (Table 1). An average of 43 participants attended each MAP intervention.

\section{Survey Results}

A total of 1330 adults (10.5\% of overall population) participated in MAP between 2012 and 2016, and of those, 898 contributed data for analysis (Table 1). Of these, 499 (56\%) attended two to four MAP education sessions before completing a post-intervention knowledge attainment survey and were considered "MAP participants," whereas 399 (44\%) had no exposure to the MAP education curriculum before completing a knowledge survey and were considered "no MAP" or "non-MAP participants." A sub-set of 266 participants (30\%) completed both a pre- and post-intervention knowledge surveys, with exposure to the MAP curriculum in between.

Baseline characteristics of the study participants are tabulated in Table 3. The average age was 37 years old (range: $18-88$ years) and the average education level completed was Grade 9 (range: Grade 0.5 - Grade 12 and above). Twenty-eight percent (253 of 898 ) of participants were male. The number of MAP participants varied by year, due to the number of villages selected to implement MAP (range: three to seven) (Table 1). Almost $44 \%$ of participants self-reported that they had previously had a malaria episode themselves, whereas $62.2 \%$ reported that someone in their household had a malaria episode. 
Table 3.

Baseline characteristics of Malaria Awareness Program (MAP) study participants, South Africa 2012 - 2016

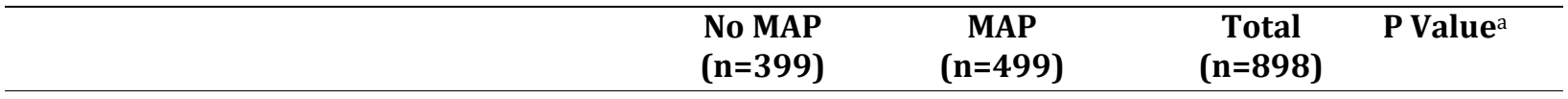

Demographics

Education - grade completed ${ }^{\mathrm{b}}$

$\begin{array}{lrrr}0-8 & 163(46 \%) & 145(32 \%) & 308(38 \%) \\ >8-<12 & 122(34 \%) & 219(48 \%) & 341(42 \%) \\ 12+ & 71(20 \%) & 95(21 \%) & 166(20 \%)\end{array}$

$<0.0$

01

ge - years

$\begin{array}{lrrr}\text { Mean (SD) } & 38.2(14.4) & 36.1(12.8) & 37.0(13.6) \\ 18-30 & 135(35 \%) & 182(37 \%) & 317(36 \%) \\ 30-<40 & 95(24 \%) & 156(32 \%) & 251(28 \%) \\ 40+ & 161(41 \%) & 156(32 \%) & 317(36 \%)\end{array}$

0.00

7

Gender

Male

$126(32 \%)$

$127(25 \%)$

$273(68 \%)$

$372(75 \%)$

$253(28 \%)$

$645(72 \%)$

Year of participation

2012

2013

2014

2015

2016

$\begin{array}{rr}92(23 \%) & 128(26 \%) \\ 64(16 \%) & 153(31 \%) \\ 54(14 \%) & 53(11 \%) \\ 79(20 \%) & 100(20 \%) \\ 110(28 \%) & 65(13 \%)\end{array}$

No. (\%) displayed, except otherwise noted

No $\mathrm{MAP}=$ attended one meeting; $\mathrm{MAP}=$ attended two to four meetings

a Chi-squared tests

b NOTE: Each "grade completed" above 12, indicates one year in university

\section{$\underline{\text { Malaria Knowledge }}$}

Knowledge of malaria symptoms was greater across eight out of ten symptom types among MAP participants, compared to non-MAP participants (Table 4). Notable differences in symptom knowledge included, diarrhea (40.9\% MAP, $22.3 \%$ no MAP), headache $(73.0 \%$ MAP, 55.6\% no MAP), and shivering /convulsion (38.5\% MAP, $24.3 \%$ no MAP). Although the majority of participants were able to correctly list some symptoms of malaria before participating in MAP, symptoms most frequently recognized upon completion of MAP 
coincided with the symptoms mentioned in the Malaria Anthem (Table 4 \& 5). This highlights the potential impact of the interactive Malaria Anthem as a means to stimulate knowledge of symptoms.

Differences in knowledge of malaria transmission and prevention methods were found (Table 4). There was a 20.6\% (51.9\% MAP, 31.3\% no MAP) and 12.4\% (3.6\% MAP, 16.0\% no MAP) difference in the proportion of participants who cited correct and partially correct transmission methods, respectively. "Correct" transmission methods included: mosquito parasite, not using preventative measures, dirty items such as trash attract mosquitos, and association with standing dirty water. "Incorrect" transmission methods included: drinking/using dirty water and "other" factors such as weak immune system, poor hygiene, eating unripe fruit or bad food, and transmission via flies, animals, or other parasites (Figures 4a and 4b, Supplemental Materials). There was an 11.9\% (95.4\% MAP, 83.5\% no MAP) and $21.1 \%$ (28.3\% MAP, 49.4\% no MAP) difference in the proportion of participants who cited correct and incorrect malaria prevention methods, respectively. Of correct preventative measures identified by community members, "Allow Malaria Control to spray homes" had a 16\% difference (72.1\% MAP, 56.1\% no MAP) (Table 10, Supplemental Materials). Other correct prevention methods such as wearing long clothing and filling holes to avoid collecting rainwater were more commonly cited in surveys taken by those who attended MAP. 
Table 4.

Malaria symptoms, transmission methods, and prevention methods as reported by participants in the MAP Study, South Africa 2012 - 2016

\begin{tabular}{|c|c|c|c|c|}
\hline & $\begin{array}{l}\text { No MAP } \\
(n=399)\end{array}$ & $\begin{array}{l}\text { MAP } \\
(n=499)\end{array}$ & $\begin{array}{l}\% \\
\text { Difference }\end{array}$ & P Value \\
\hline \multicolumn{5}{|l|}{ SYMPTOMS } \\
\hline Body/joint pains, can't walk & $42(10.5)$ & $72(14.4)$ & +3.9 & 0.08 \\
\hline Diarrhea $^{\mathbf{b}}$ & $89(22.3)$ & $204(40.9)$ & +18.6 & $<0.001$ \\
\hline Fever, warm, cold, sweat & $156(39.1)$ & $163(32.7)$ & -6.4 & 0.05 \\
\hline Headache ${ }^{b}$ & $222(55.6)$ & $364(73.0)$ & +17.3 & $<0.001$ \\
\hline Lack of appetite, loss of weight & $31(7.8)$ & $44(8.8)$ & +1.0 & 0.57 \\
\hline Nausea, stomach ache & $25(6.3)$ & $67(13.4)$ & +7.2 & $<0.001$ \\
\hline Shivering, convulsions $\mathbf{b}$ & $97(24.3)$ & $192(38.5)$ & +14.2 & $<0.001$ \\
\hline Tiredness, dizziness, drowsy, feeling weak & $97(24.3)$ & $88(17.6)$ & -6.7 & 0.01 \\
\hline Vomiting, get sick $\mathbf{b}$ & $145(36.3)$ & $203(40.7)$ & +4.3 & 0.19 \\
\hline Other & $8(2.0)$ & $18(3.6)$ & +1.6 & 0.16 \\
\hline
\end{tabular}

\begin{tabular}{|c|c|c|c|c|}
\hline \multicolumn{5}{|l|}{ TRANSMISSION METHODS } \\
\hline Mention of mosquitos or mosquito bites & $366(84.2)$ & $458(91.8)$ & +7.6 & $<0.001$ \\
\hline Methods deemed "correct" & $140(31.3)$ & $292(51.9)$ & +20.6 & $<0.001$ \\
\hline Methods deemed "incorrect" & $72(16.0)$ & $19(3.6)$ & -12.4 & $<0.001$ \\
\hline $\begin{array}{l}\text { No mention of mosquitos or mosquito } \\
\text { bites }\end{array}$ & $52(13.0)$ & $24(4.8)$ & -8.2 & $<0.001$ \\
\hline \multicolumn{5}{|l|}{ PREVENTION METHODS } \\
\hline Methods deemed "correct" & $604(83.5)$ & $1020(95.4)$ & +11.9 & $<0.001$ \\
\hline Methods deemed "incorrect" & $238(49.4)$ & $147(28.3)$ & -21.1 & $<0.001$ \\
\hline
\end{tabular}

No. (\%) displayed, except otherwise noted

No $\mathrm{MAP}=$ attended one meeting; $\mathrm{MAP}=$ attended two to four meetings

a Chi-squared tests

${ }^{\mathrm{b}}$ Indicates symptom that was emphasized through the Malaria Anthem

\section{MAP Sub-analysis Malaria Knowledge}

There were significant improvements in malaria knowledge within the sub-analysis

of MAP participants who completed both pre- and post-surveys (Table 5). There was a nine

percent increase in the proportion of participants who cited mosquitos or mosquito bites as

a method of malaria transmission, as well as a $21.4 \%$ and $10.5 \%$ increase in the proportion

of participants who cited correct malaria transmission and prevention methods, respectively

(Table 5).

Participants who completed MAP perceived the program to be rewarding and

effective, with mostly positive evaluations (Table 9, Supplemental Materials). On a scale of 
one to five (1: lowest rating, 5 : highest rating), $94 \%$ - $98 \%$ of participants rated questions

assessing program evaluation as four or greater (Table 6).

Table 5.

Malaria symptoms, transmission methods, and prevention methods as reported by participants in the MAP Study Sub-Analysis, South Africa 2012 - 2016

\begin{tabular}{|c|c|c|c|c|}
\hline & $\begin{array}{l}\text { Pre-survey } \\
(n=266)\end{array}$ & $\begin{array}{l}\text { Post-survey } \\
(n=266)\end{array}$ & $\%$ Change & P Value $^{a}$ \\
\hline \multicolumn{5}{|l|}{ SYMPTOMS } \\
\hline Body/joint pains, can't walk & $24(9.0)$ & $31(11.7)$ & +2.6 & 0.32 \\
\hline Diarrhea $^{\mathbf{b}}$ & $50(18.8)$ & $91(34.2)$ & +15.4 & $<0.001$ \\
\hline Fever, warm, cold, sweat & $118(44.4)$ & $87(32.7)$ & -11.7 & 0.006 \\
\hline Headache $\mathbf{b}$ & $145(54.5)$ & $190(71.4)$ & +16.9 & $<0.001$ \\
\hline Lack of appetite, loss of weight & $21(7.9)$ & $22(8.3)$ & +0.4 & 0.87 \\
\hline Nausea, stomach ache & $18(6.8)$ & $36(13.5)$ & +6.8 & 0.01 \\
\hline Shivering, convulsions $\mathbf{b}^{\mathbf{b}}$ & $74(27.8)$ & $96(36.1)$ & +8.3 & 0.04 \\
\hline Tiredness, dizziness, drowsy, feeling weak & $72(27.1)$ & $36(13.5)$ & -13.5 & $<0.001$ \\
\hline Vomiting, get sick $\mathbf{b}$ & $99(37.2)$ & $97(36.5)$ & -0.8 & 0.86 \\
\hline Other & $3(1.1)$ & $5(1.9)$ & +0.8 & 0.48 \\
\hline \multicolumn{5}{|l|}{ TRANSMISSION METHODS } \\
\hline Mention of mosquitos or mosquito bites & $222(83.5)$ & $246(92.5)$ & +9.0 & 0.001 \\
\hline Methods deemed "correct" & $92(32.0)$ & $153(53.4)$ & +21.4 & $<0.001$ \\
\hline Methods deemed "incorrect" & $46(16.2)$ & $15(5.3)$ & -10.9 & $<0.001$ \\
\hline $\begin{array}{l}\text { No mention of mosquitos or mosquito } \\
\text { bites }\end{array}$ & $37(13.9)$ & $16(6.0)$ & -7.9 & 0.002 \\
\hline \multicolumn{5}{|l|}{ PREVENTION METHODS } \\
\hline Methods deemed "correct" & $393(84.6)$ & $494(95.1)$ & +10.5 & 0.001 \\
\hline Methods deemed "incorrect" & $149(44.4)$ & $77(27.1)$ & -17.3 & $<0.001$ \\
\hline
\end{tabular}

Table 6.

Program Evaluation of MAP study participants, South Africa $2012-2016$

\begin{tabular}{|c|c|c|c|}
\hline \multirow{2}{*}{$\begin{array}{l}\text { Question } \\
(\mathrm{N}=266, \text { Likert Scale: } 1-5)\end{array}$} & \multicolumn{2}{|c|}{ No (\%) } & \multirow{2}{*}{$\begin{array}{l}\text { Mean } \\
\text { (SD) }\end{array}$} \\
\hline & Score $=5$ & $\begin{array}{c}\text { Score }= \\
\quad 4\end{array}$ & \\
\hline How much do you feel you learned about malaria through MAP? & $\begin{array}{c}231 \\
(88.9)\end{array}$ & $14(5.4)$ & $4.8(0.7)$ \\
\hline How much did you enjoy MAP? & $\begin{array}{c}238 \\
(91.2)\end{array}$ & $17(6.5)$ & $4.9(0.5)$ \\
\hline How likely would you be to suggest MAP to a friend? & $\begin{array}{c}243 \\
(94.2)\end{array}$ & $5(1.9)$ & $4.9(0.6)$ \\
\hline $\begin{array}{l}\text { How likely would you be to return as a MAP participant again next } \\
\text { year? }\end{array}$ & $\begin{array}{c}245 \\
(94.2)\end{array}$ & $7(2.7)$ & $4.9(0.6)$ \\
\hline
\end{tabular}




\section{Multiple Ordinal Logistic Regression}

This analysis compared study participants who completed the MAP intervention through attendance at two to four education sessions $(n=499)$ versus those who did not complete the MAP intervention ( $n=399$ ). The adjusted odds ratio for correct malaria knowledge score versus the combined partially correct and incorrect categories was 3.3 (95\% Cl: $2.2-4.9, p$-value $<0.001)$ and 2.8 (95\% Cl: $2.0-3.7$, p-value $<0.001)$ for transmission and prevention, respectively (Table 7). The results from fitting the model on imputed data versus incomplete age data led to similar results, and no interaction between the MAP intervention and age was present.

Table 7.

Unadjusted and adjusted cumulative odds ratios of participants' malaria knowledge score in the MAP Study, South Africa $2012-2016$ ( $n=898$ )

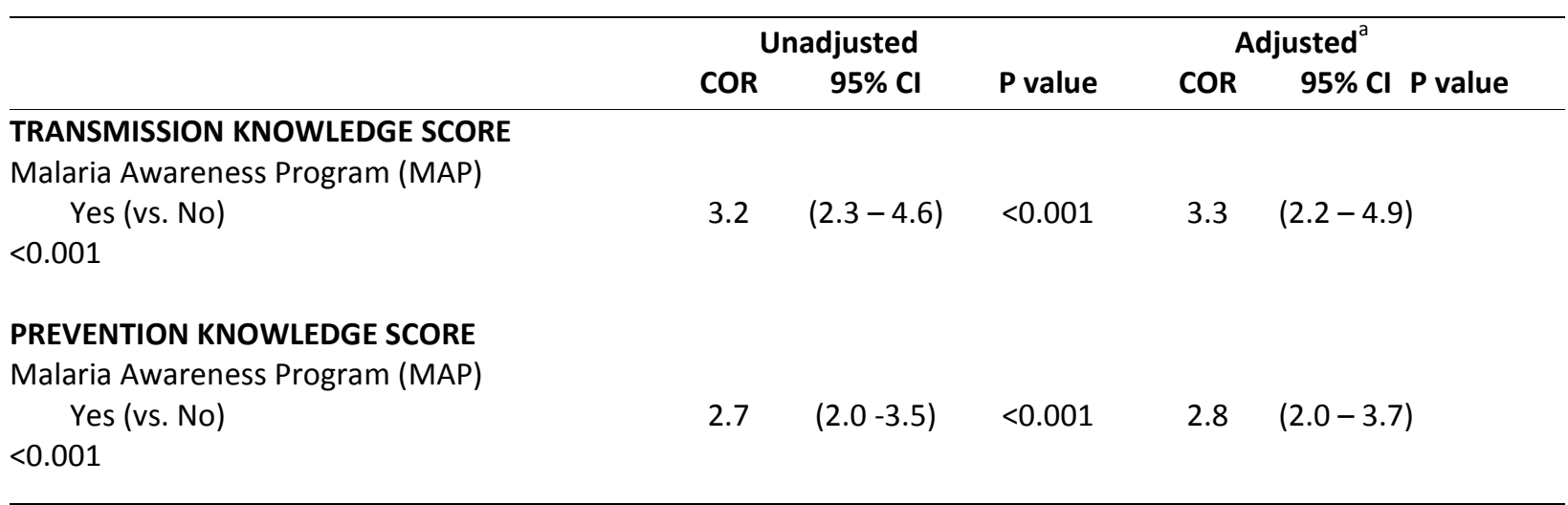

${ }^{a}$ Adjusted for education, age, gender, and year based on multiple ordinal logistic regression

\section{Community Acceptability}

MAP was reported to have generated positive responses from the community by officials attending monthly Makuya Intersectoral Committee Meetings during the intervention period. ${ }^{14}$ Exit interviews with $\mathrm{HBC}$ workers and provincial Malaria Control representatives revealed a strong desire to continue to implement the program, as well as to expand future education programs using participatory methods similar to those employed in MAP. For example, a HBC worker from Domboni stated, "We enjoyed the unity 
that came from working together and helping the community together." A nurse assistant at the local Makuya clinic noted, "The research and outreach MAP is doing is helping us because once people know the symptoms [of malaria] they are actually coming to the clinic." High community and stakeholder acceptability of MAP strengthened the long-term success of the program by building capacity of OSH as a trusted local non-profit organization. Additionally, the strong partnership established with the Limpopo Department of Health Malaria Control Programme through MAP enabled OSH to pursue expansion opportunities, as well as additional programs such as a social entrepreneurship initiative designed to improve economic mobility of women in the region.

\section{Discussion}

The objective of this study was to evaluate the community-led Malaria Awareness Program and determine whether participation in MAP was associated with an increase in knowledge of malaria transmission, symptoms, prevention, or treatment based on pre- and post-surveys.

\section{Malaria Knowledge}

The MAP pre-survey data revealed that the largest gap in community knowledge was related to transmission and prevention. While general knowledge of malaria in all four focus areas increased after participation in MAP workshops, the most drastic improvements were seen within transmission and prevention. Adjusted regression results suggest that MAP participants were more knowledgeable than non-participants in transmission and prevention methods. This association did not change in the sensitivity analyses. 


\section{$\underline{\text { Transmission knowledge }}$}

Although most participants correctly cited mosquitoes as the primary malaria transmission vector before MAP, many individuals also mentioned incorrect methods. It is possible that these individuals previously learned that mosquitos cause malaria without adequate detailed explanation. Similar pre-intervention findings are documented in the literature, especially with regard to the misconception that mosquitos are not the causative agent of malaria. ${ }^{15}$ This partial understanding of the relationship between malaria and mosquito bites indicates an incomplete knowledge of malaria, which has been correlated with poor adherence to measures of vector control. ${ }^{16}$ Common misconceptions in both the literature and the MAP study included beliefs that "drinking dirty water" and "eating unripe fruits" cause malaria. ${ }^{16,17}$ To address these misconceptions, HBC workers leading MAP thus described the malaria transmission cycle through diagrams, with emphasis on the physiology of a malaria-infected individual as this was where the majority of participants' questions arose. As a result, participants indicated a complete understanding of the parasite that causes malaria 13\% more often upon completion of MAP (Table 10, Supplemental Materials).

\section{Prevention knowledge}

While participants often mentioned effective prevention methods prior to MAP, they commonly indicated uncertainty regarding personal protection behaviors and had difficulty articulating the importance of preventative methods. After participating in MAP workshops, however, there was a decrease in the number of incorrect prevention measures cited (Table 5). One preventative measure emphasized throughout the intervention was IRS using DDT, as IRS is South Africa's primary malaria vector control strategy and thus is highly advocated for by the government. Many indicated that they were skeptical of the effectiveness of IRS 
chemicals, while others questioned the trustworthiness of Malaria Control representatives who spray. To address these concerns during the intervention, workshop leaders held open discussions to emphasize the benefits of spraying. Previous literature indicates the importance of clarifying incorrect associations that may threaten the effectiveness of proper prevention and control measures. ${ }^{15}$

$\underline{\text { Implications }}$

Increased understanding of malaria may have an effect on community participation in malaria control efforts. For example, many MAP participants expressed increased trust in Malaria Control spraying insecticides in their homes. One participant indicated that after MAP he would now allow "Malaria Control team to spray our house every time."

Additionally, participants mentioned their plans to spread malaria education throughout their community. As malaria prevalence shrinks and subclinical cases persist, it will be imperative to maintain community engagement and enthusiasm. Community education programs may play a key role in raising awareness and participation in malaria control efforts that are necessary in the fight toward malaria elimination.

\section{MAP in the Context of Malaria Education Literature}

Nine other malaria education intervention studies implemented in other SubSaharan countries were identified and analyzed for comparison to MAP. No previous malaria education studies measuring knowledge change in South Africa were identified (Table 9, Supplemental Materials). All malaria studies selected for comparison to MAP measured knowledge of participants through questionnaires and/or semi-structured interviews, however, each study assessed knowledge differently. While MAP utilized an ordinal knowledge score which included "correct," "partially correct," or "incorrect" (range: 0 - 2), many studies used binary assessments such as "good" or "right" and "poor" or 
"wrong." $17,18,19$ Other methods included categorical scores ${ }^{20}$ and scores based on number or percentage of responses. ${ }^{16,21}$

The majority of malaria education programs have focused on malaria during pregnancy and among children under five, ${ }^{17,18,22}$ however, MAP retained a broad, adult target population as advised by senior officials from the South African Department of Health. South Africa's malaria burden is less heavily tied to children and pregnant women, as migrant workers who carry malaria across borders pose a specific and serious risk to nonimmune individuals. ${ }^{23,24}$ Thus, it was deemed appropriate to include both male and female community members over the age of 18 in MAP workshops.

MAP was similar to other malaria education interventions in its utilization of interactive activities (Table 9, Supplemental Materials). Like MAP, common activities in the literature included utilizing charts/posters, pictures, songs, drama, role-play, and group discussion. ${ }^{16,17,18,19,20,22,25,26}$ These were often vaguely described in the literature, thus it is difficult to compare exact similarities and differences to activities in MAP.

MAP's length fell between the range of identified intervention lengths (one day - 18 months) and the range of timing of assessment (directly following intervention - one year after the intervention) (Table 9, Supplemental Materials). The number of annual participants varied depending on the number of villages selected to participate in the program (Table 1, Table 3). The predictor variable of "year" thus indicated some significance in the cumulative odds ratios of participants' malaria knowledge score. For example with the prevention knowledge score, confidence intervals overlapped one for each year except 2015 and 2016 (Table 12, Supplemental Materials). This significance may be due to MAP's programmatic adjustment from four to three workshops in 2015 and 2016. 
MAP was unique in its training and use of HBC workers as peer educators. In Limpopo there is a severe shortage of clinical staff, with only 1.8 doctors per 10,000 patients. ${ }^{27}$ Thus, while other studies utilized health workers such as medical doctors, nurses, field workers, and other primary health care staff, only MAP utilized HBC workers to lead the intervention. In the Vhembe District, $\mathrm{HBC}$ workers work closely with local clinics and play a more general community health worker role. Respected by the communities they work in, HBC workers were selected as ideal advocates to develop, inform, and lead MAP. While this worked well in this particular setting, it is important to note that this form of leadership may not be suitable for other regions.

\section{Capacity Building of a Local Non-Profit}

In addition to its impact on community knowledge of malaria, MAP provided a key opportunity for OSH as a small, local non-profit organization to build its capacity to operate within and provide support to the Limpopo Province. Through MAP, OSH developed strong partnerships with local stakeholders and the Limpopo Department of Health Malaria Control Programme. These key relationships enabled its operation as an organization focused on public health in this region. OSH adopted learnings and best practices from the implementation and evaluation of MAP to modify its programs and overall approach to best address community needs, as well as partner with government and local stakeholders to mobilize and provide resources.

Non-profit organizations are instrumental in building research capacity, delivering essential services in hard-to-reach communities, and contributing to local development in health around the world. ${ }^{28,29,30}$ MAP's deep integration and acceptance by the local community and the Department of Health strengthened OSH's capacity as a local non-profit 
organization, enabling it to continue to support research and provide services to address pertinent health needs in the future.

\section{Limitations}

The findings from this study indicate that MAP may be a framework for future malaria education strategies in South Africa, but key limitations exist. As the MAP study design utilized a volunteer sample and lacked a randomized control group, the findings are associational and there is a potential threat to internal validity. Some villages had poor attendance at workshops due to community engagements such as funerals, cultural rituals, and government pension days. Additionally, the measurement of knowledge based on number of MAP meetings attended may not account for confounding factors such as oral communication and village social networks, where people may have learned about malaria through word-of-mouth outside of MAP workshops. Central adjudication was used to interpret survey responses in an attempt to minimize misclassification, however, language barriers led to difficulty in complete translation. Two different interpreters were used in translating surveys, which may have led to inconsistencies.

Selection bias and non-differential measurement error may also be present as it is plausible that those who attended more MAP workshops had increased motivation and interest in learning about malaria than individuals who attended fewer or no workshops. Gender may play a role, as over $70 \%$ of MAP participants were female. Additionally, adult males are typically mobile and spend considerable time outside compared to women and children who are protected by their sprayed homes. ${ }^{31}$ Based on cultural and prior knowledge, it was postulated that age and/or education level may have influenced an individual's decision to participate in MAP. Sensitivity analyses were run to look at missing data through multiple imputation for education level, as well as potential interaction 
between intervention, age, and education level. No significant bias was shown between intervention and age or education level. Another notable limitation is that participants may have skewed their answers to please educators responsible for collecting the surveys. This may have caused some respondents to downplay beliefs such as the use of traditional medicine, and/or exaggerate the importance of seeking treatment from the clinic or allowing preventative DDT spraying by Malaria Control.

While improvement in participant knowledge of those who correctly sighted malaria transmission and prevention methods is encouraging, this study did not analyze long-term retention of knowledge. It is important to understand at what point knowledge wanes to inform whether refresher training is needed yearly before malaria season. Finally, it is worth noting that possessing scientific knowledge of malaria does not necessarily imply 'correct' malaria control behavior and preventative action taken. While understanding of malaria transmission, symptoms, prevention, and treatment is an important factor in disease prevention and community empowerment, behavior change has the greatest direct impact on disease incidence.

\section{Conclusion}

This study highlights the success of a participatory health education program to increase malaria knowledge and awareness, as well as presents implications for future malaria programming and capacity building in rural settings. First, $\mathrm{HBC}$ workers represent a strong group of front-line health workers who can provide group education effectively with training. In communities with complex governance structures, it is critical that malaria programming engage stakeholders at all levels - local, regional, and national - appropriately. Interactive educational curricula, involving song, theatre, and other forms of active discussion, appear to be an effective method to engage community members and increase 
knowledge and awareness about malaria. Improved knowledge of malaria transmission and prevention after MAP was positively correlated with attendance at workshops, indicating the effectiveness of a multi-step education process. As malaria prevalence decreases and subclinical cases persist, health promotion will play an imperative role in maintaining community participation in malaria control efforts toward malaria elimination.

Currently, there are a large number of studies measuring malaria knowledge, however, there is a gap in the research measuring malaria education interventions impact on knowledge. The MAP model has potential to be easily replicable in comparable settings where minimal resources and low levels of malaria remain. Additionally, the development of similar programs may provide capacity building opportunities for local nonprofits, as well as strengthen nonprofit and government partnerships. Future research should look at developing health promotion solutions and testing these interventions to improve community understanding of malaria. Further, behavioral changes toward prevention and treatment, as well as changes in overall incidence in the region, should be assessed.

While malaria education programs can empower community members to better understand, prevent, and treat disease, education is just one of many control strategies that should be explored to effectively combat malaria. To best determine long-term implications of the MAP, follow-up surveys on malaria knowledge retention and preventative behaviors are recommended six months to one year after initial exposure to education. MAP and the Limpopo Department of Health Malaria Control Programme can learn from these data and presented analyses to better strategize and plan for future health promotion and malaria control. 


\section{Acknowledgements}

The authors would like to thank the communities of HaMakuya and Masisi for their active participation, cooperation, interest, and feedback in the Malaria Awareness Program; the home-based care workers who acted as peer educators, Malaria Control representatives, Makuya Tribal Council, Makuya Clinic, and the Intersectoral Committee for their support and guidance. The authors would also like to acknowledge the Department of Health Malaria Control for providing support and feedback. This intervention would not have been possible without partnership from Nsasani Trust and the Organization for Tropical Studies (OTS), specifically Dr. Laurence Kruger, Dr. Alex Müller, and Dr. Kate Abney Barreiro, and Tshulu Trust, specifically Melta Makuya, Fhatuwani Makuya, and Dr. Lara Allen. The authors would like to thank MAP co-founder Danielle Jessen as well as past and present MAP Coordinators who supported program facilitation and data collection: Melissa Manus, Victoria Skinner, Sruti Pisharody, Jacqueline Treiger, Temi Adebayo, Juliette Fry, Kayla McAvoy, George Mauype, Alexandra (Sasha) Giedd, and Kristin Andrejko. MAP's translators were essential to the success of the program and include Tovhowanni Innocent Kwinda, Sigwadi Thuseni, Tinyiko Given Baloyi, Thabelo Innocent Thanyani, and Marelyn Khubana. The Malaria Awareness Program was funded by DukeEngage, Duke ChangeWorks, Gephardt Institute for Public Service Cantor Social Change Grant, The Resolution Project, University of Miami Butler Center for Service, and private donations.

Conflict of Interest Disclosures: The views expressed in this article are those of the authors and not necessarily those of One Sun Health and its various funders. 


\section{References}

${ }^{1}$ Malaria Fact Sheet. (2016). World Health Organization. Retrieved from http://www.who.int/mediacentre/factsheets/fs094/en/

${ }^{2}$ Cotter C., Sturrock H.J., Hsiang M.S., Liu J., Phillips A.A., Hwang J., Gueye C.S., Fullman N., Gosling R.D., Feachem R.G. (2013). The changing epidemiology of malaria elimination: new strategies for new challenges. The Lancet. 382:900-11. DOI 10.1016/S01406736(13)60310-4.

${ }^{3}$ Moonasar D., Nuthulaganti T., Kruger P.S., Mabuza, A., Rasiswi, E.S., Benson, F.G. (2012). Malaria control in South Africa 2000-2010: beyond MDG6. Malaria Journal. 11:294. DOI 10.1186/1475-2875-11-294.

${ }^{4}$ Khosa E., Kuonza L., Kruger P., Maimela E. (2013). Towards the elimination of malaria in South Africa: a review of surveillance data in Mutale Municipality, Limpopo Province, 2005 to 2010. Malaria Journal. 12:7. DOI 10.1186/1475-2875-12-7.

${ }^{5}$ Raman, J., Morris, N., Frean, J., Brooke, B., Blumberg, L., Kruger, P., Mabusa, A., Raswiswi, E., Shandukani, B., Misani, E., Groepe, M., Moonasar, D. (2016). Reviewing South Africa's malaria elimination strategy (2012-2018): progress, challenges and priorities. Malaria Journal. 15:438. DOI 10.1186/s12936-016-1497-x.

${ }^{6}$ Malaria Strategic Plan 2012-2018: Mid-term Review. (2015). World Health Organization. Retrieved from http://www.afro.who.int/en/south-africa/pressmaterials/item/7978-malaria-strategic-plan-2012-2018-mid-term-review.html.

${ }^{7}$ Malaria elimination strategy for South Africa 2012-2018. (2012). South Africa National Department of Health. Retrieved from http://www.ccoat.uct.ac.za/publishedguidelines.

${ }^{8}$ Nyunt, M.H., Aye, K.M., Kyaw, M.P., Wai, K.T., Oo, T., Than, A., Oo, H.W., Phway, H.P., Han,S.S., Htun, T., San, K.K. (2015). Evaluation of the behaviour change communication and community mobilization activities in Myanmar artemisinin resistance containment zones. Malaria Journal. 14:522. DOI 10.1186/s12936-0151047-y.

${ }^{9}$ Malaria Behavior Change Communication (BCC) Indicator Reference Guide. (2014). Roll Back Malaria Partnership (RBM). Retrieved from http://www.rollbackmalaria.org/files/files/resources/Malaria-BCC-IndicatorsReference-Guide.pdf.

${ }^{10}$ Koenker, H., Keating, J., Alilio, M., Acosta, A., Lynch, M., \& Nafo-Traore, F. (2014). Strategic roles for behaviour change communication in a changing malaria landscape. Malaria Journal. 13:1. DOI 10.1186/1475-2875-13-1. 
${ }^{11}$ One Sun Health. (2017). One Sun Health, Inc. Retrieved from http://www.onesunhealth.org

${ }^{12}$ Community Home-Based Care in Resource-Limited Settings: A Framework for Action. (2002). World Health Organization. Retrieved from http://www.who.int/chp/knowledge/publications/comm_home_based_care/e n/

${ }^{13}$ Stata StataCorp. (2013). Stata Statistical Software: Release 13. College Station, TX: StataCorp LP.

${ }^{14}$ Nemaheni, A. (2015). Interview by S. Cox [Tape recording]. One Sun Health: The Malaria Awareness Program. Limpopo, South Africa.

15 Legesse, M., \& Deressa, W. (2009). Community awareness about malaria, its treatment and mosquito vector in rural highlands of central Ethiopia. The Ethiopian Journal of Health Development. 23:40-47.

${ }^{16}$ Ayi, I., Nonaka, D., Adjovu, J.K., Hanafusa, S., Jimba, M., Bosompem, K.M., Mizoue, T., Takeuchi, T., Boakye, D.A., Kobayashi, J. (2010). School-based participatory health education for malaria control in Ghana: Engaging children as health messengers. Malaria Journal. 9:98 DOI 10.1186/1475-2875-9-98.

${ }^{17}$ Nkuo Akenji, T.K., Ntonifor, N.N., Ching, J.K., Kimbi, H.K., Ndamukong, K.N., Anong, D.N., Boyo, M.G., Titanji, V.P. (2005). Evaluating a malaria intervention strategy using knowledge, practices and coverage surveys in rural Bolifamba, Southwest Cameroon. Transactions of the Royal Society of Tropical Medicine and Hygiene, 99(5):325-332. DOI 10.1016/j.trstmh.2003.12.016.

${ }^{18}$ Amoran, O.E. (2013). Impact of health education intervention on malaria prevention practices among nursing mothers in rural communities in Nigeria. Nigerian Medical Journal. 54(2):115. DOI 10.4103/0300-1652.110046.

${ }^{19}$ Chirdan, O.O., Zoakah, A.I., \& Ejembi, C.L. (2008). Impact of health education on home treatment and prevention of malaria in Jengre, North Central Nigeria. Annals of African Medicine. 7(3):112-119.

${ }^{20}$ Akogun O.B. (1992). The effect of selected health education schemes on knowledge and attitude of the Kanuri towards certain parasitic diseases. Journal of the Royal Society of Health. 112(6):280-285.

${ }^{21}$ Rhee, M., Sissoko,M. Perry, S., McFarland, W., Parsonnet, J., Doumbo, O. (2005). Use of insecticide-treated nets (ITNs) following a malaria education intervention in Piron, Mali: a control trial with systematic allocation of households. Malaria Journal. 4:35. DOI 10.1186/1475-2875-4-35. 
${ }^{22}$ Mens, P.F., Scheelbeek, P.F., Al Atabbi, H., \& Enato, E.F. (2011). Peer education: The effects on knowledge of pregnancy related malaria and preventive practices in women of reproductive age in Edo State, Nigeria. BMC Public Health. 11:610. DOI 10.1186/1471-2458-11-610.

${ }^{23}$ Kruger, Philippus. (30 October 2014). Interview by S. Cox [Email]. One Sun Health: The Malaria Awareness Program. Limpopo, South Africa.

${ }^{24}$ Maharaj, R., Raman, J., Morris, N., Moonasar, D., Durrheim, D.N., Seocharan, I., Kruger, P., Shandukani, B., Kleinschmidt, I. (2013). Epidemiology of malaria in South Africa: From control to elimination. South African Medical Journal. 103(10 Suppl 2):779-783. DOI 10.7196/SAMJ.7441.

${ }^{25}$ Marsh, V.M., Mutemi, W., Some, E.S., Haaland, A., \& Snow, R.W. (1996). Evaluating the community education programme of an insecticide-treated bed net trial on the Kenyan coast. Health Policy and Planning. 11(3):280-291.

${ }^{26}$ Oreagba, I.A. (2005). Outcome of a face - face educational strategy on awareness and treatment knowledge of malaria amongst caregivers of young children in a rural community in southwest Nigeria. Nigerian Quarterly Journal of Hospital Medicine. 15(2):45-49.

${ }^{27}$ Wildschut, Angelique. (2016). Doctors in the public service too few for too many. Human Sciences Research Council (HSRC). Retrieved from: http://www.hsrc.ac.za/en/review/november-/public-service-doctors.

28 Delisile, Hélène. (2005). The role of NGOs in global health research for development. Health Research Policy and Systems. 3:3. DOI: 10.1186/1478-4505-3-3.

${ }^{29}$ Nelson, Jane. (2007). The Operation of Non-Governmental Organizations (NGOs) in a World of Corporate and Other Codes of Conduct. Corporate Social Responsibility Initiative, Working Paper No. 34. Cambridge, MA: John F. Kennedy School of Government, Harvard University. Retrieved from: https://www.hks.harvard.edu/centers/mrcbg/programs/cri/research/papers.

${ }^{30}$ Nishtar, Sania. (2004). Public - private 'partnerships' in health - a global call to action. Health Research Policy and Systems. 2:5. DOI 10.1186/1478-4505-2-5.

${ }^{31}$ Kruger, Philippus. (07 February 2017). Interview by S. Cox [Email]. One Sun Health: The Malaria Awareness Program. Limpopo, South Africa. 


\section{Supplemental Materials}

Table 8.

Search Terms

\section{Search Terms}

\begin{tabular}{|c|c|}
\hline Filter 1 & "Malaria" \\
\hline Filter 2 & $\begin{array}{l}\text { "health education" or "knowledge change" or "community-based education" or "community-based } \\
\text { education intervention" or "community-based program" or "community-based intervention" or educate } \\
\text { or education or educating or knowledge or perception or attitude or awareness or aware or learn or } \\
\text { learning or teach or teacher or teaching or taught or "peer education" or "peer educate" or "peer } \\
\text { educator" or peer-education or peer-educate or peer-educator }\end{array}$ \\
\hline Filter 3 & 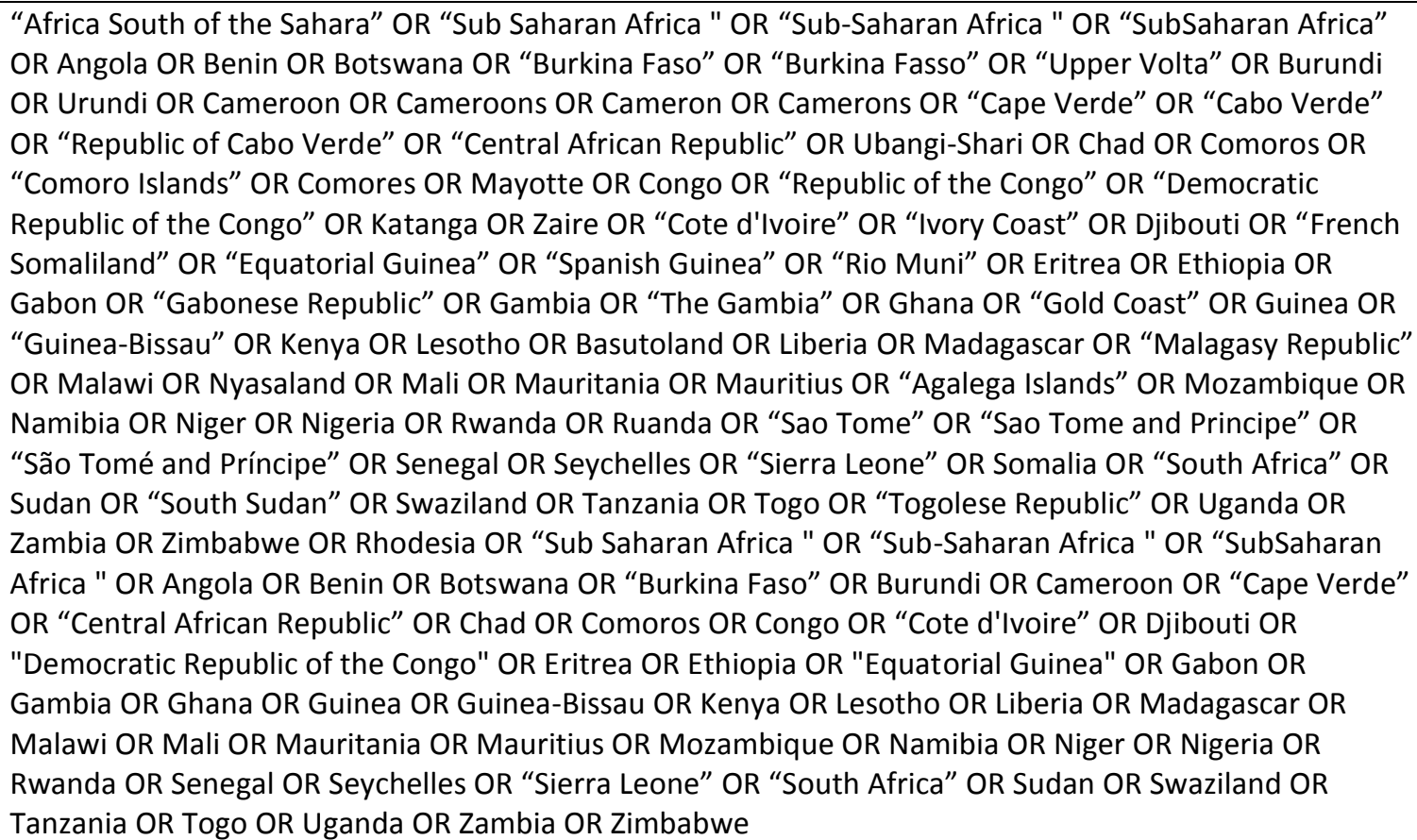 \\
\hline
\end{tabular}


Table 9.

\begin{tabular}{|c|c|c|c|c|c|c|c|c|c|}
\hline Authan & Pear & Ceuntry & Trant Population & Astorvemitian & Autivitios & Inplementatian Methodt & $\begin{array}{c}\text { Tine-framie of } \\
\text { ntarvemian } \\
\text { Eapesure }\end{array}$ & 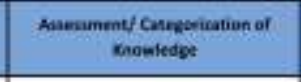 & $\begin{array}{l}\text { Effuets en Fractice } \\
\text { Measured theoieh }\end{array}$ \\
\hline Amoran & 2013 & $\begin{array}{l}\text { Nigkila } \\
\text { (nurd) }\end{array}$ & 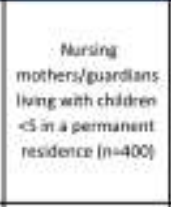 & 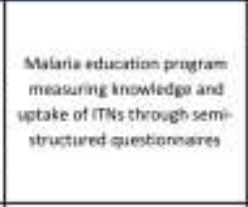 & 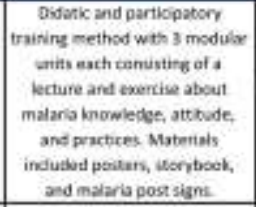 & $\begin{array}{l}\text { Leaders of intervertion nat } \\
\text { idantifed Sutvers adnisistered by } 8 \\
\text { research assigants fcommonity } \\
\text { heolth extengion workersy }\end{array}$ & $\begin{array}{l}\text { Anturvemion: } 1 \text { day, } 5 \\
\text { haues: Awiessmint, } 3 \\
\text { months afte } \\
\text { intervertion }\end{array}$ & $\begin{array}{l}\text { "Goof - malaria is raused by } \\
\text { mosqubo insect; "Poor" = octer }\end{array}$ & Cumitimares. \\
\hline $\begin{array}{l}\text { Mens et } \\
\text { al. }\end{array}$ & 2011 & $\begin{array}{l}\text { Nigers } \\
\text { Iuthan S } \\
\text { frall }\end{array}$ & 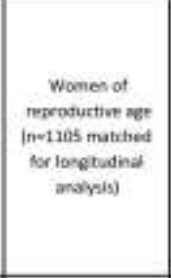 & $\begin{array}{l}\text { Pear ta peer malatia educatimn } \\
\text { messurireg knowiedge of MPP } \\
\text { through structured } \\
\text { questionnaim }\end{array}$ & 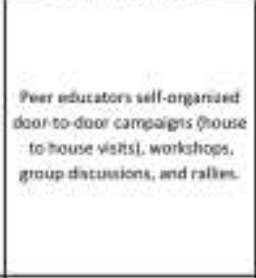 & $\begin{array}{l}30 \text { pees educators selected from } \\
\text { commurity led the intervention. } \\
\text { Sepirati inturviewen in }=12 \text { ) and } \\
\text { supervisors in }-2 \text { ) were recruited } \\
\text { from the studf communices }\end{array}$ & $\begin{array}{l}\text { intervemion: not } \\
\text { stabed, Assessment: } 6 \\
\text { months atter } \\
\text { mtervertion }\end{array}$ & 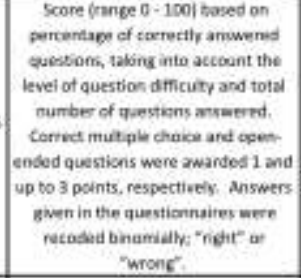 & Questimmares \\
\hline Asset al & 2010 & $\begin{array}{l}\text { Ghans } \\
\text { lutasn } 8 \\
\text { nuali }\end{array}$ & $\begin{array}{l}\text { Sctrod dilidren in } \\
\text { grades } 3.5 \text { in-186) } \\
\text { a aduit comminity } \\
\text { members (n=393) }\end{array}$ & 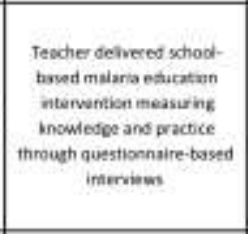 & 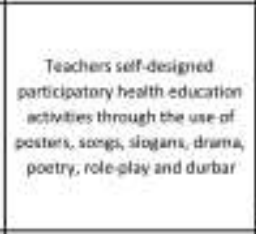 & 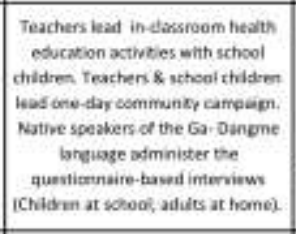 & 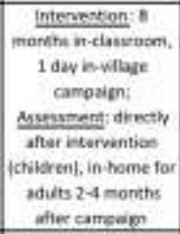 & 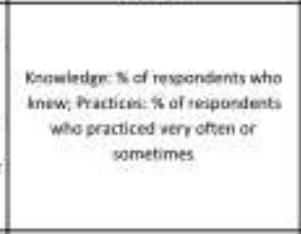 & 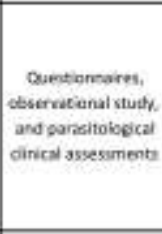 \\
\hline $\begin{array}{l}\text { Ctirndon } \\
\text { et al }\end{array}$ & 2009 & $\begin{array}{l}\text { Nigeris } \\
\text { |urtianj }\end{array}$ & 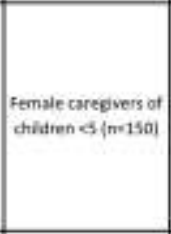 & 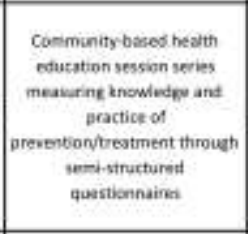 & 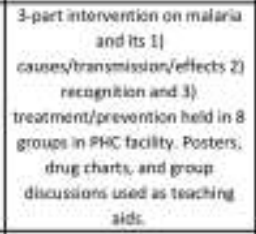 & 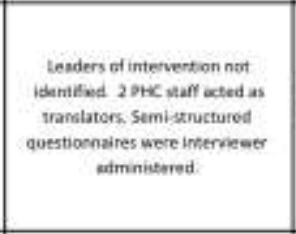 & 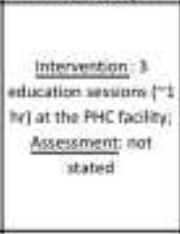 & 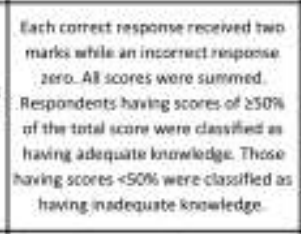 & Quesoomares \\
\hline Nowno et & 2005 & $\begin{array}{c}\text { Cainesoon } \\
\text { (rutalls }\end{array}$ & $\begin{array}{c}\text { Mothers of chilisen } \\
\text { ated 55 veirs } \\
\text { (n-185) }\end{array}$ & 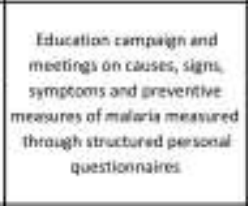 & 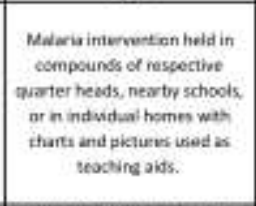 & 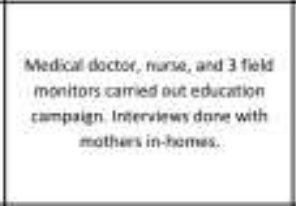 & 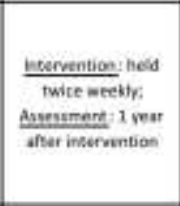 & 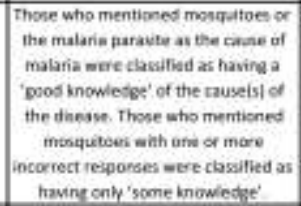 & $\begin{array}{l}\text { Ouestiomnaires and } \\
\text { clincal asvesuments }\end{array}$ \\
\hline $\begin{array}{l}\text { Ahere a } \\
2 .\end{array}$ & 2005 & $\begin{array}{c}\text { Mali } \\
\text { (ruad) }\end{array}$ & $\begin{array}{l}\text { Addat contminhy } \\
\text { memben mint } \\
\text { ctilaren }(\ln -276)\end{array}$ & 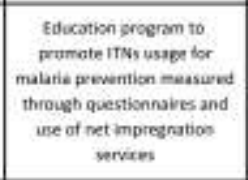 & 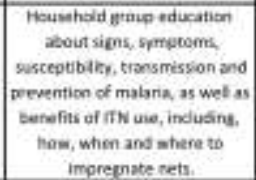 & 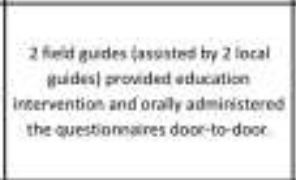 & $\begin{array}{l}\text { Intervemicon net } \\
22 \text { das after } \\
\text { mitervention }\end{array}$ & 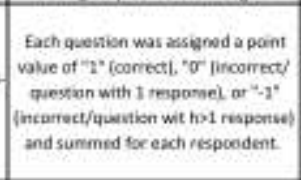 & 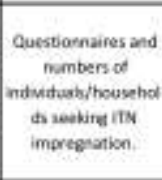 \\
\hline Oreaga & 2005 & $\begin{array}{l}\text { Nigeris } \\
\text { (pural! }\end{array}$ & $\begin{array}{l}\text { Carers of young } \\
\text { childien (mo-60) }\end{array}$ & 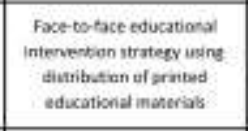 & $\begin{array}{c}\text { Printed edveational leaflets } \\
\text { mth pictorial alustrations, one. } \\
\text { os-one trainirg }\end{array}$ & 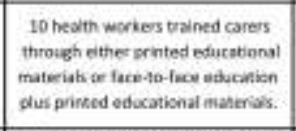 & $\begin{array}{l}\text { interwertion } 1 \text { vist } \\
\text { Assisimem: a } \\
\text { baseline, I and } 3 \\
\text { months after } \\
\text { intarvertion }\end{array}$ & 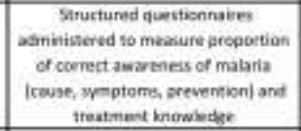 & Questiomaires \\
\hline $\begin{array}{l}\text { Markin } x \\
\text { i. }\end{array}$ & 1995 & $\begin{array}{l}\text { Rentya } \\
\text { hural }\end{array}$ & 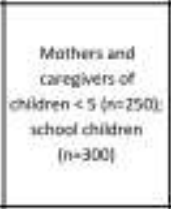 & 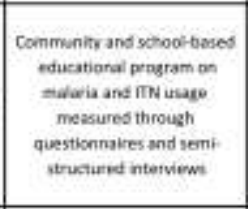 & 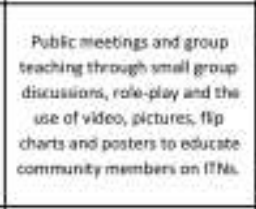 & 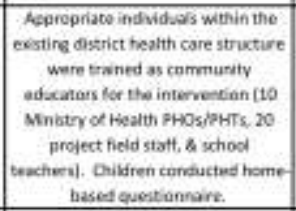 & 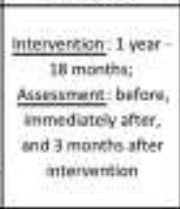 & Not specified & Cuetionares \\
\hline Abogun & 1992 & Nigeria & $\begin{array}{c}\text { Community } \\
\text { members innt tasy }\end{array}$ & 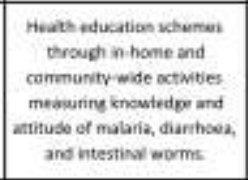 & 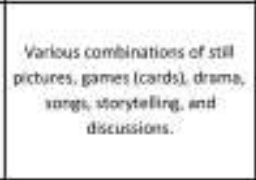 & 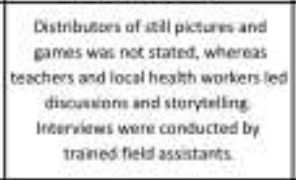 & 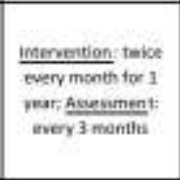 & 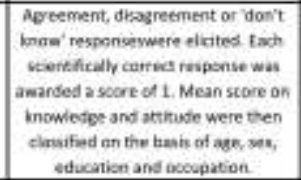 & $\begin{array}{l}\text { Cuestionnsires and } \\
\text { chirical akvesuments }\end{array}$ \\
\hline
\end{tabular}


Table 10.

Malaria symptoms, transmission methods, and prevention methods as reported by participants in MAP Study, South Africa 2012 - 2016

\begin{tabular}{|c|c|c|c|c|}
\hline & $\begin{array}{l}\text { No MAP } \\
(n=399)\end{array}$ & $\begin{array}{l}\text { MAP } \\
(n=499)\end{array}$ & $\begin{array}{l}\% \\
\text { Difference }\end{array}$ & P Value $^{\text {a }}$ \\
\hline \multicolumn{5}{|l|}{ SYMPTOMS } \\
\hline Body/joint pains, can't walk & $42(10.5)$ & $72(14.4)$ & +3.9 & 0.08 \\
\hline Diarrhea $^{\mathrm{b}}$ & $89(22.3)$ & $204(40.9)$ & +18.6 & $<0.001$ \\
\hline Fever, warm, cold, sweat & $156(39.1)$ & $163(32.7)$ & -6.4 & 0.05 \\
\hline Headache $^{b}$ & $222(55.6)$ & $364(73.0)$ & +17.3 & $<0.001$ \\
\hline Lack of appetite, loss of weight & $31(7.8)$ & $44(8.8)$ & +1.0 & 0.57 \\
\hline Nausea, stomach ache & $25(6.3)$ & $67(13.4)$ & +7.2 & $<0.001$ \\
\hline Shivering, convulsions ${ }^{b}$ & $97(24.3)$ & $192(38.5)$ & +14.2 & $<0.001$ \\
\hline Tiredness, dizziness, drowsy, feeling weak & $97(24.3)$ & $88(17.6)$ & -6.7 & 0.01 \\
\hline Vomiting, get sick $^{b}$ & $145(36.3)$ & $203(40.7)$ & +4.3 & 0.19 \\
\hline Other & $8(2.0)$ & $18(3.6)$ & +1.6 & 0.16 \\
\hline \multicolumn{5}{|l|}{ TRANSMISSION METHODS } \\
\hline Mention of mosquitos or mosquito bites & $366(84.2)$ & $458(91.8)$ & +7.6 & $<0.001$ \\
\hline Methods deemed "correct" & $140(31.3)$ & $292(51.9)$ & +20.6 & $<0.001$ \\
\hline Mosquito parasite & $48(12.0)$ & $125(25.1)$ & +13.0 & $<0.001$ \\
\hline Not using preventative measures & $49(12.3)$ & $128(25.7)$ & +13.4 & $<0.001$ \\
\hline Dirty house, items attract mosquitos & $15(3.8)$ & $19(3.8)$ & +0.0 & 0.97 \\
\hline Association with standing, dirty water & $25(6.3)$ & $19(3.8)$ & -2.5 & 0.09 \\
\hline Methods deemed "incorrect" & $72(16.0)$ & $19(3.6)$ & -12.4 & $<0.001$ \\
\hline Drinking/ using dirty, contaminated, unpurified, or river water & $49(12.3)$ & $11(2.2)$ & -10.1 & $<0.001$ \\
\hline Other & $20(5.0)$ & $7(1.4)$ & -3.6 & 0.002 \\
\hline No mention of mosquitos or mosquito bites & $52(13.0)$ & $24(4.8)$ & -8.2 & $<0.001$ \\
\hline Drinking/using dirty, contaminated, unpurified, or river water & $24(6.0)$ & $10(2.0)$ & -4.0 & 0.002 \\
\hline Dirty house, items & $12(3.0)$ & $10(2.0)$ & -1.0 & 0.33 \\
\hline Not using preventative measures & $13(3.3)$ & $21(4.2)$ & +1.0 & 0.48 \\
\hline Other & $35(8.8)$ & $6(1.2)$ & -7.6 & $<0.001$ \\
\hline \multicolumn{5}{|l|}{ PREVENTION METHODS } \\
\hline Methods deemed "correct" & $604(83.5)$ & $1020(95.4)$ & +11.9 & $<0.001$ \\
\hline $\begin{array}{l}\text { Allow Malaria Control to spray homes; Avoid cleaning walls after } \\
\text { spraying }\end{array}$ & $224(56.1)$ & $360(72.1)$ & +16.0 & $<0.001$ \\
\hline $\begin{array}{l}\text { Wear long clothing, cover-up exposed body; Stay inside during } \\
\text { sunrise and sunset }\end{array}$ & $72(18.1)$ & $171(34.3)$ & +16.2 & $<0.001$ \\
\hline Close windows & $20(5.0)$ & $72(14.4)$ & +9.4 & $<0.001$ \\
\hline $\begin{array}{l}\text { Fill holes/throw away trash/dirty things/empty tins (relation to } \\
\text { rainwater and mosquitos) }\end{array}$ & $21(5.3)$ & $61(12.2)$ & +7.0 & $<0.001$ \\
\hline Mosquito coils & $54(13.5)$ & $98(19.6)$ & +6.1 & 0.02 \\
\hline Avoid stagnant water (with relation to mosquitos) & $22(5.5)$ & $39(7.8)$ & +2.3 & 0.17 \\
\hline Mosquito nets, bed nets & $87(21.8)$ & $125(25.1)$ & +3.3 & 0.26 \\
\hline Cut holes in tires to drain water & $0(0.0)$ & $8(1.6)$ & +1.6 & 0.01 \\
\hline Keep yard/house clean (relation to mosquitos) & $12(3.0)$ & $24(4.8)$ & +1.8 & 0.17 \\
\hline Other mosquito repellants & $38(9.5)$ & $22(4.4)$ & -5.1 & 0.002 \\
\hline Receive education & $48(12.0)$ & $35(7.0)$ & -5.0 & 0.01 \\
\hline Methods deemed "incorrect" & $238(49.4)$ & $147(28.3)$ & -21.1 & $<0.001$ \\
\hline Call EMS; Go to the clinic; Get medication & $80(20.1)$ & $42(8.4)$ & -11.6 & $<0.001$ \\
\hline Use/drink clean water, not dirty/river water & $53(13.3)$ & $16(3.2)$ & -10.1 & $<0.001$ \\
\hline Keep yard/house clean (no relation to rainwater or mosquitos) & $71(17.8)$ & $66(13.2)$ & -4.6 & 0.06 \\
\hline Traditional methods (burn cow dung /musudzungwane tree) & $7(1.8)$ & $21(4.2)$ & +2.5 & 0.04 \\
\hline Other & $23(5.8)$ & $2(0.4)$ & -5.4 & $<0.001$ \\
\hline
\end{tabular}

No. (\%) displayed, except otherwise noted

No $\mathrm{MAP}=$ attended one meeting; $\mathrm{MAP}=$ attended two to four meetings

${ }^{\text {a }}$ Chi-squared tests

${ }^{b}$ Indicates symptom that was emphasized through Malaria Anthem

${ }^{\mathrm{c}}$ Mean (SD) 
Table 11.

Malaria symptoms, transmission methods, and prevention methods as reported by participants in MAP Study, South Africa 2012 - 2016

\begin{tabular}{|c|c|c|c|c|}
\hline & $\begin{array}{l}\text { Pre-survey } \\
(\mathrm{n}=266)\end{array}$ & $\begin{array}{l}\text { Post-survey } \\
(\mathrm{n}=266)\end{array}$ & \% Change & P Value $^{\text {a }}$ \\
\hline \multicolumn{5}{|l|}{ SYMPTOMS } \\
\hline Body/joint pains, can't walk & $24(9.0)$ & $31(11.7)$ & +2.6 & 0.32 \\
\hline Diarrhea $^{\mathrm{b}}$ & $50(18.8)$ & $91(34.2)$ & +15.4 & $<0.001$ \\
\hline Fever, warm, cold, sweat & $118(44.4)$ & $87(32.7)$ & -11.7 & 0.006 \\
\hline Headache ${ }^{b}$ & $145(54.5)$ & $190(71.4)$ & +16.9 & $<0.001$ \\
\hline Lack of appetite, loss of weight & $21(7.9)$ & $22(8.3)$ & +0.4 & 0.87 \\
\hline Nausea, stomach ache & $18(6.8)$ & $36(13.5)$ & +6.8 & 0.01 \\
\hline Shivering, convulsions ${ }^{b}$ & $74(27.8)$ & $96(36.1)$ & +8.3 & 0.04 \\
\hline Tiredness, dizziness, drowsy, feeling weak & $72(27.1)$ & $36(13.5)$ & -13.5 & $<0.001$ \\
\hline Vomiting, get sick ${ }^{b}$ & $99(37.2)$ & $97(36.5)$ & -0.8 & 0.86 \\
\hline Other & $3(1.1)$ & $5(1.9)$ & +0.8 & 0.48 \\
\hline \multicolumn{5}{|l|}{ TRANSMISSION METHODS } \\
\hline Mention of mosquitos or mosquito bites & $222(83.5)$ & $246(92.5)$ & +9.0 & 0.001 \\
\hline Methods deemed "correct" & $92(32.0)$ & $153(53.4)$ & +21.4 & $<0.001$ \\
\hline Mosquito parasite & $34(12.8)$ & $63(23.7)$ & +10.9 & 0.001 \\
\hline Not using preventative measures & $32(12.0)$ & $66(24.8)$ & +12.8 & $<0.001$ \\
\hline Dirty house, items attract mosquitos & $9(3.4)$ & $14(5.3)$ & +1.9 & 0.29 \\
\hline Association with standing, dirty water & $14(5.3)$ & $9(3.4)$ & -1.9 & 0.29 \\
\hline Methods deemed "incorrect" & $46(16.2)$ & $15(5.3)$ & -10.9 & $<0.001$ \\
\hline Drinking/ using dirty, contaminated, unpurified, or river water & $30(11.3)$ & $9(3.4)$ & -7.9 & $<0.001$ \\
\hline Other & $15(5.6)$ & $5(1.9)$ & -3.8 & 0.02 \\
\hline No mention of mosquitos or mosquito bites & $37(13.9)$ & $16(6.0)$ & -7.9 & 0.002 \\
\hline Drinking/using dirty, contaminated, unpurified, or river water & $18(6.8)$ & $5(1.88)$ & -4.9 & 0.006 \\
\hline Dirty house, items & $13(4.9)$ & $6(2.3)$ & -2.6 & 0.10 \\
\hline Not using preventative measures & $9(3.4)$ & $10(3.8)$ & +0.4 & 0.82 \\
\hline Other & $25(9.4)$ & $3(1.1)$ & -8.3 & $<0.001$ \\
\hline \multicolumn{5}{|l|}{ PREVENTION METHODS } \\
\hline Methods deemed "correct" & $393(84.6)$ & $494(95.1)$ & +10.5 & 0.001 \\
\hline $\begin{array}{l}\text { Allow Malaria Control to spray homes; Avoid cleaning walls after } \\
\text { spraying }\end{array}$ & $151(56.8)$ & $180(67.7)$ & +10.9 & 0.01 \\
\hline $\begin{array}{l}\text { Wear long clothing, cover-up exposed body; Stay inside during } \\
\text { sunrise and sunset }\end{array}$ & $47(17.7)$ & $92(34.6)$ & +16.9 & $<0.001$ \\
\hline Close windows & $23(8.6)$ & $25(9.4)$ & +0.8 & 0.76 \\
\hline $\begin{array}{l}\text { Fill holes/throw away trash/dirty things/empty tins (relation to } \\
\text { rainwater and mosquitos) }\end{array}$ & $13(4.9)$ & $26(9.8)$ & +4.9 & 0.03 \\
\hline Mosquito coils & $28(10.5)$ & 37 (13.9) & +3.4 & 0.23 \\
\hline Avoid stagnant water (with relation to mosquitos) & $13(4.9)$ & $22(8.3)$ & +3.4 & 0.12 \\
\hline Mosquito nets, bed nets & $46(17.3)$ & $62(23.3)$ & +6.0 & 0.09 \\
\hline Cut holes in tires to drain water & $1(0.4)$ & $2(0.8)$ & +0.4 & 0.56 \\
\hline Keep yard/house clean (relation to mosquitos) & $11(4.1)$ & $13(4.9)$ & +0.8 & 0.68 \\
\hline Other mosquito repellants & $17(6.4)$ & $10(3.8)$ & -2.6 & 0.17 \\
\hline Receive education & $41(15.4)$ & $21(7.9)$ & -7.5 & 0.007 \\
\hline Methods deemed "incorrect" & $149(44.4)$ & $77(27.1)$ & -17.3 & $<0.001$ \\
\hline Call EMS; Go to the clinic; Get medication & $44(16.5)$ & $24(9.0)$ & -7.5 & 0.009 \\
\hline Use/drink clean water, not dirty/river water & $29(10.9)$ & $10(3.8)$ & -7.1 & 0.002 \\
\hline Keep yard/house clean (no relation to rainwater or mosquitos) & $50(18.8)$ & $32(12.0)$ & -6.8 & 0.03 \\
\hline Traditional methods (burn cow dung /musudzungwane tree) & $4(1.5)$ & $9(3.4)$ & +1.9 & 0.16 \\
\hline Other & $20(7.5)$ & $2(0.8)$ & -6.8 & $<0.001$ \\
\hline
\end{tabular}

No. (\%) displayed, except otherwise noted

${ }^{a}$ Chi-squared tests

${ }^{\mathrm{b}}$ Indicates symptom that was emphasized through Malaria Anthem

${ }^{c}$ Mean (SD) 
Table 12.

Unadjusted and adjusted cumulative odds ratios of participants' malaria knowledge score in the MAP Study, South Africa 2012 - 2016

\begin{tabular}{|c|c|c|c|c|c|c|}
\hline & \multicolumn{2}{|c|}{ Unadjusted } & \multicolumn{4}{|c|}{ Adjusted* } \\
\hline & COR & $95 \% \mathrm{Cl}$ & $P$ value & COR & $95 \% \mathrm{Cl}$ & $P$ value \\
\hline \multicolumn{7}{|c|}{ TRANSMISSION KNOWLEDGE SCORE } \\
\hline \multicolumn{7}{|c|}{ Malaria Awareness Program (MAP) } \\
\hline Yes (vs. No) & 3.2 & $(2.3-4.6)$ & $<0.001$ & 3.3 & $(2.2-4.9)$ & $<0.001$ \\
\hline \multicolumn{7}{|l|}{ Education - grade completed } \\
\hline $0-8$ (reference) & 1.0 & & & 1.0 & & \\
\hline$>8-<12$ & 1.5 & $(1.0-2.2)$ & 0.04 & 1.7 & $(1.1-2.5)$ & 0.02 \\
\hline $12+$ & 1.6 & $(1.0-2.6)$ & $\begin{array}{l}0.05 \\
0.05^{\mathrm{a}}\end{array}$ & 2.2 & $(1.3-4.0)$ & $\begin{array}{l}0.006 \\
0.01^{\mathrm{a}}\end{array}$ \\
\hline \multicolumn{7}{|l|}{ Age-years } \\
\hline $18-<30$ (reference) & 1.0 & & & 1.0 & & \\
\hline $30-<40$ & 2.2 & $(1.4-3.4)$ & 0.001 & 2.3 & $(1.4-3.6)$ & 0.001 \\
\hline \multirow[t]{2}{*}{$40+$} & 1.3 & $(0.9-1.9)$ & 0.15 & 2.1 & $(1.3-3.4)$ & 0.001 \\
\hline & & & $0.002^{\mathrm{a}}$ & & & $<0.001^{\mathrm{a}}$ \\
\hline \multicolumn{7}{|l|}{ Gender } \\
\hline Female (vs. Male) & 1.1 & $(0.8-1.6)$ & 0.57 & 1.1 & $(0.8-1.7)$ & 0.54 \\
\hline \multicolumn{7}{|l|}{ Year } \\
\hline 2012 (reference) & 1.0 & & & 1.0 & & \\
\hline 2013 & 0.8 & $(0.5-1.3)$ & 0.34 & 0.5 & $(0.3-0.9)$ & 0.02 \\
\hline 2014 & 0.6 & $(0.3-0.9)$ & 0.03 & 0.5 & $(0.3-0.9)$ & 0.02 \\
\hline 2015 & 1.0 & $(0.6-1.8)$ & 0.87 & 0.8 & $(0.5-1.4)$ & 0.45 \\
\hline \multirow{2}{*}{2016} & 1.0 & $(0.0-1.0)$ & 1.00 & 1.0 & $(0.6-1.8)$ & 0.92 \\
\hline & & & $0.12^{\mathrm{a}}$ & & & $0.03^{\mathrm{a}}$ \\
\hline \multicolumn{7}{|c|}{ PREVENTION KNOWLEDGE SCORE } \\
\hline \multicolumn{7}{|c|}{ Malaria Awareness Program (MAP) } \\
\hline Yes (vs. No) & 2.7 & $(2.0-3.5)$ & $<0.001$ & 2.8 & $(2.0-3.7)$ & $<0.001$ \\
\hline \multicolumn{7}{|c|}{ Education - grade completed ${ }^{\mathrm{b}}$} \\
\hline $0-8$ (reference) & 1.0 & & & 1.0 & & \\
\hline$>8-<12$ & 1.6 & $(1.2-2.2)$ & 0.003 & 1.5 & $(1.0-2.1)$ & 0.03 \\
\hline \multirow[t]{2}{*}{$12+$} & 2.2 & $(1.5-3.3)$ & $<0.001$ & 2.4 & $(1.5-3.6)$ & $<0.001$ \\
\hline & & & $<0.001^{\mathrm{a}}$ & & & $<0.001^{\mathrm{a}}$ \\
\hline \multicolumn{7}{|l|}{ Age-years } \\
\hline $18-<30$ (reference) & 1.0 & & & 1.0 & & \\
\hline $30-<40$ & 1.1 & $(0.8-1.5)$ & 0.76 & 1.0 & $(0.7-1.5)$ & 0.85 \\
\hline \multirow[t]{2}{*}{$40+$} & 0.8 & $(0.6-1.1)$ & 0.19 & 1.1 & $(0.7-1.6)$ & 0.76 \\
\hline & & & $0.25^{\mathrm{a}}$ & & & $0.95^{\mathrm{a}}$ \\
\hline \multicolumn{7}{|l|}{ Gender } \\
\hline Female (vs. Male) & 1.4 & $(1.0-1.8)$ & 0.04 & 1.4 & $(1.0-2.0)$ & 0.04 \\
\hline \multicolumn{7}{|l|}{ Year } \\
\hline 2012 (reference) & 1.0 & & & 1.0 & & \\
\hline 2013 & 1.2 & $(0.8-1.7)$ & 0.39 & 1.0 & $(0.7-1.5)$ & 0.88 \\
\hline 2014 & 1.1 & $(0.7-1.7)$ & 0.79 & 1.2 & $(0.7-1.9)$ & 0.57 \\
\hline 2015 & 2.2 & $(1.5-3.3)$ & $<0.001$ & 2.0 & $(1.3-3.1)$ & 0.003 \\
\hline \multirow[t]{2}{*}{2016} & 1.3 & $(0.9-1.9)$ & 0.19 & 1.5 & $(0.9-2.4)$ & 0.10 \\
\hline & & & $0.004^{\mathrm{a}}$ & & & $0.02^{\mathrm{a}}$ \\
\hline
\end{tabular}

*Adjusted for education, age, gender, and year based on multiple ordinal logistic regression model

${ }^{a}$ Overall significance for categorical variable (measured through testparm)

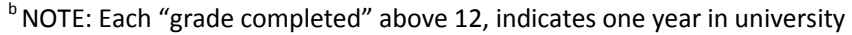


Figure 1a.

Malaria Risk Map, South Africa (Source South African Medical Research Council)

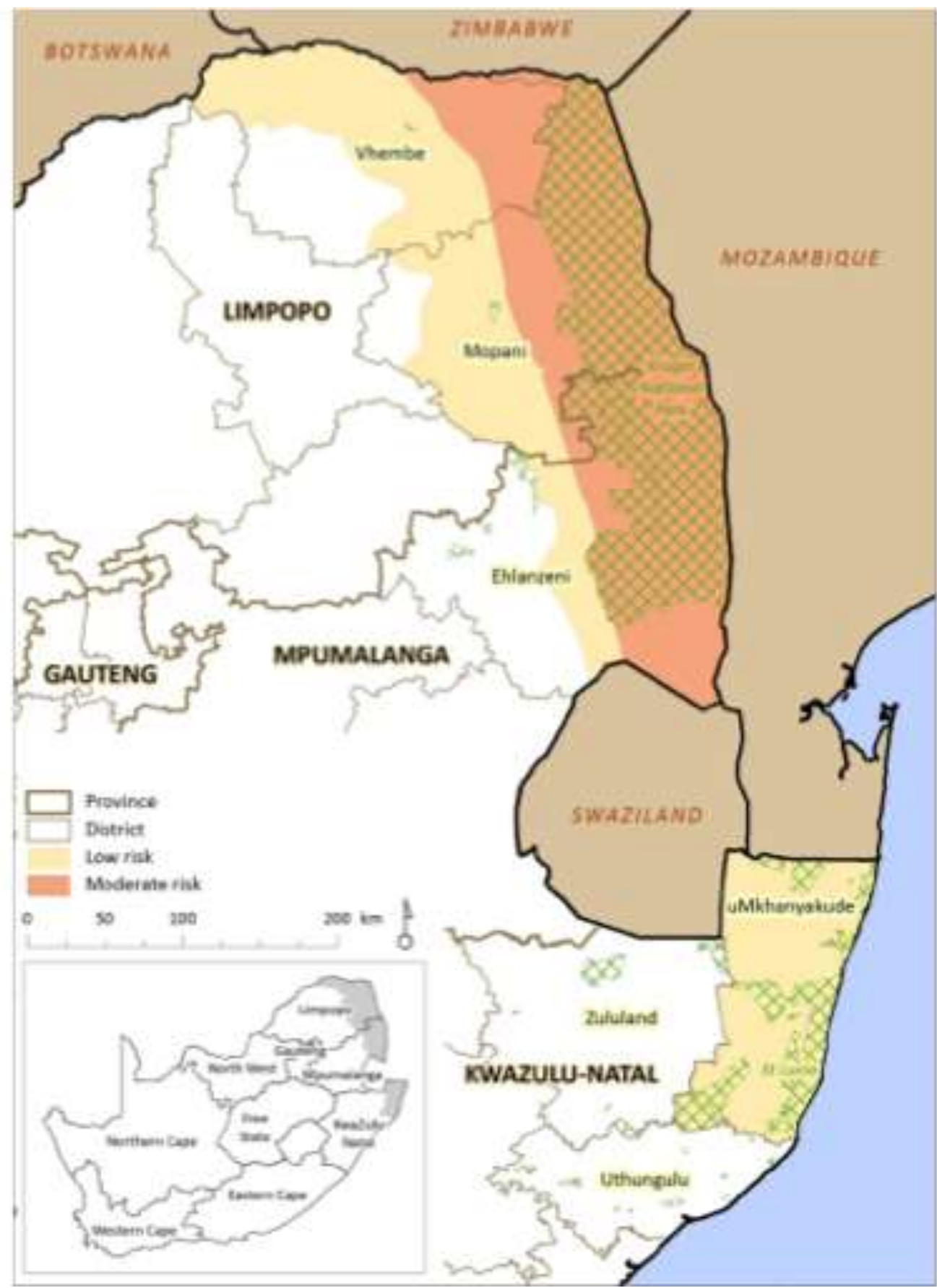

* Cross-hatched areas are game reserves 
Figure $1 b$.

Vhembe District Map, South Africa (Source Google)

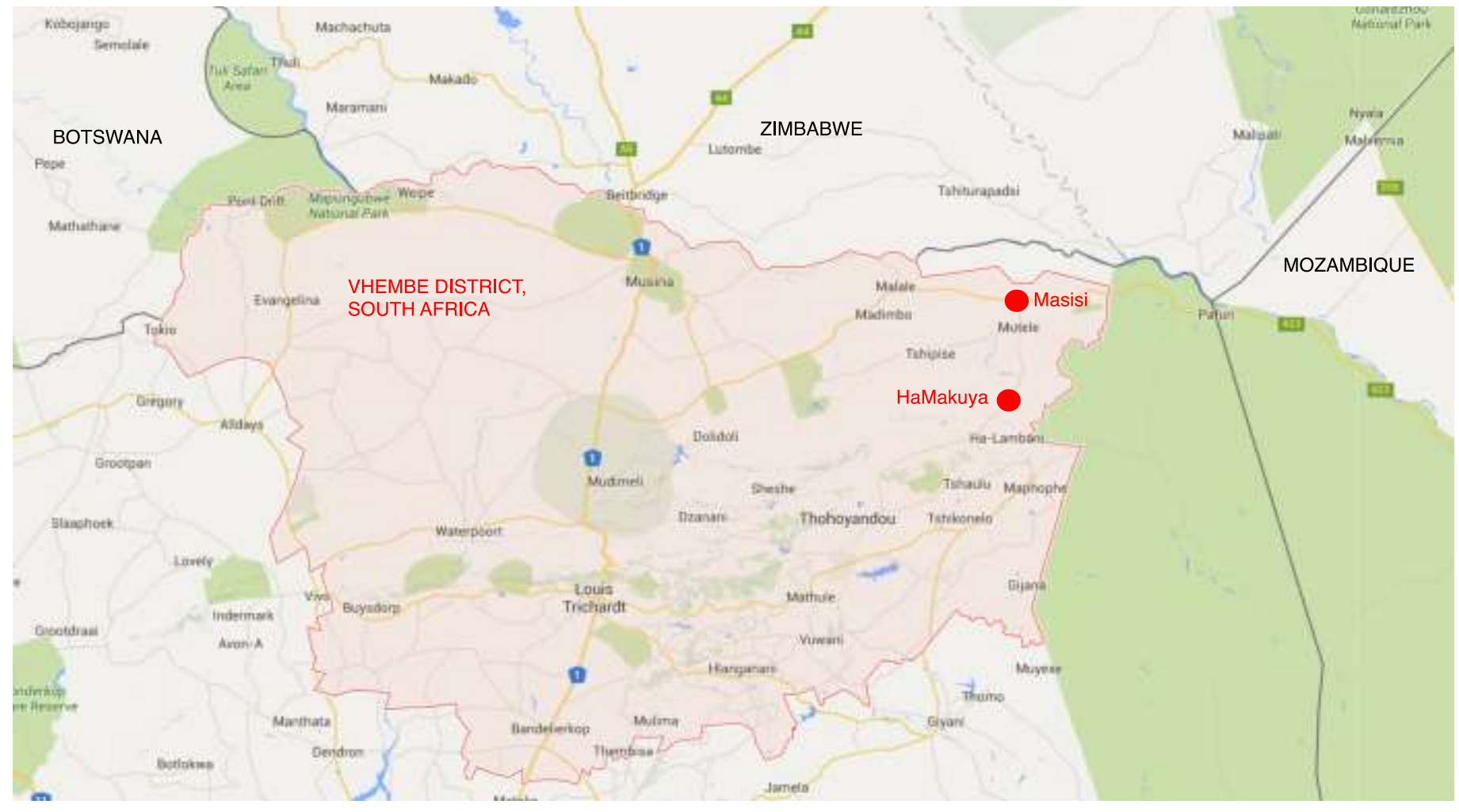

38 
Figure 2.

Detailed Overview of MAP Peer Education Program

\section{Meeting 1: Local Etiology of Malaria}

Goal: build upon what people already know about malaria, biological responses, the body, sickness in general, etc.

- Opening: welcome, apologies, attendance

- Informed consent and release packet

- Give each participant the informed consent and release packet. Ask participants to sign the informed consent and release. After, collect the packets.

- Distribute pre-surveys

- Assess existing knowledge

- Malaria Web Activity: Lead a discussion where participants build a web of words that they associate with malaria. After the web is filled, peer-educators should discuss each word and whether or not it has a correct association with malaria.

- Focus group discussions

- Divide participants into 3 equal sized groups and guide discussions while referring to Focus Group Questions. Once completed, clarify material from these group discussions.

- If audience is receptive, tell stories of personal experiences with malaria

- In the stories, consider risk factors like environment (cue on specifics - near water/vegetation, etc.), activities

- Seasonality of malaria

- Conduct trend line activity

- How does malaria come and go throughout the year? Throughout life?

- Agricultural seasons, school seasons, harvest seasons?

- Discuss transmission:

- Show and explain diagram

- Sing Malaria Anthem

- Closing: Thank you, share date of next meeting

\section{Meeting 2 (or 2-3): Malaria Education}

Goal: fully inform participants of malaria transmission, symptoms, preventive measures, and treatment seeking option while building upon local knowledge/awareness.

- Opening: welcome, apologies, attendance, minutes from last meeting

- Informed consent and release packet

- Give each participant the informed consent and release packet. Ask participants to sign the informed consent and release. After, collect the packets.

- Review transmission:

- Show and explain diagram

- Discuss symptoms:

- Human Body Activity: Participants break into two or three groups and are given a poster with the outline of a human body on it. They are asked to draw the symptoms of malaria that they know, and then present and discuss their drawings with other groups. Then, the peer educator presents the symptoms associated with malaria infection and groups will be asked to discuss how they would change their drawings given this information.

- Discuss prevention:

- Explain preventative options with suggestions tailored to individuals

- Malaria Drama: Peer educators perform a play in which malaria symptoms and prevention measures are presented through the life story of one individual who follows correct prevention measures and one who ignores prevention measures.

- Discuss treatment: Go to Makuya clinic immediate to receive the following treatments

- Give out EMS and Makuya Clinic's phone numbers 
- Sing Malaria Anthem

- Closing: Thank you, share date of next meeting

\section{Meeting 3 (or 4): Debrief, discussion \& conclude}

Goal: review basics of malaria education program, with the hope that individual participants are better aware of malaria transmission, symptoms, preventative measures, and treatment seeking options.

- Opening: welcome, apologies, attendance, minutes from last meeting

- Informed consent and release packet

- Give each participant the informed consent and release packet. Ask participants to sign the informed consent and release. After, collect the packets.

- Distribute post-surveys

- To minimize bias, ensure no review of malaria information is done before post-surveys are taken

- Open discussion and question forum

- Apply knowledge within community: Give examples of possible scenarios of malaria experiences

- Malaria Drama: Community members perform a play in which malaria symptoms and prevention measures are presented through the life story of one individual who follows correct prevention measures and one who ignores prevention measures.

- Sing Malaria Anthem

- Closing: Thank you 
Figure 3a.

Pre-Survey Malaria Questions

Dzina (Name):

Vhukale (Age):

Mbeu (Gender):

Murole wa nthesa (Education Level):

1. Vha humbula uri muthu u farwa hani nga dali? How do you think someone gets malaria?

2. Vhahumbula uri ndi ngani muthu a tshifariwa nga malaria? Why do you think someone gets malaria?

3. Vha humbula uri hu itea mini muvhilini wavho musi vhe na dali? What do you think happens to your body when you have malaria?

4. Vha humbula uri vha nga ita mini u thivhela uri vha sa farwe nga dali? What do you think you can do to prevent yourself from getting malaria?

5. Vha humbula uri tshitshavha tsha havho tshi nga ita mini u thivhela dali? What do you think your community can do to prevent malaria?

6. Vho vha vha tshi nga ita mini arali vha na tsumbadwadze dza dali? What would you do if you were showing symptoms of malaria?

7. Vho vha tshi nga ya ngafhi u wana dzilafho arali vho vha vhe na dali? Where would you go for treatment if you had malaria?

8. Zwi nga vha dzhiela tshifhinga tshingafhani u toda dzilafho nga murahu ha u vha na tsumbadwadze dza dali? How long after experiencing symptoms of malaria would you seek treatment?

9. Vhone kana munwe muthu mutani wavho o no vhuya a vha na dali? Ndi nnyi? Lini? Lungana? Have you or anyone else in your household had malaria? Who? When? How many times?

10. Huna zwinwevho zwine vha tama ri tshi zwi divha?(Mmbudziso kana vhudipfi havho?) Is there anything else you would like us to know? Questions? Comments? 
Figure 3b.

Post-Survey Malaria Questions: Mbudziso dza nga murahu ha Tsedzuluso ya Dali

Dzina (Name):

Vhukale (Age):

Mbeu (Gender):

Murole wa nthesa (Education Level):

1. Vha humbula uri muthu u wana hani dali? How do you think someone gets malaria?

2. Vha humbula uri ndi ngani muthu a tshi farwa nga dali? Why do you think someone gets malaria?

3. Vha humbula uri hu itea mini muvhilini wavho musi vhe na dali? What do you think happens to your body when you have malaria?

4. Vha humbula uri vha nga ita mini u thivhela uri vha sa farwe nga dali? What do you think you can do to prevent yourself from getting malaria?

5. Vha humbula uri tshitshavha tsha havho tshi nga ita mini u thivhela dali? What do you think your community can do to prevent malaria?

6. Vho vha vha tshi nga ita mini arali vha na tsumbadwaze dza dali? What would you do if you were showing symptoms of malaria?

7. Vho vha vha tshi nga ya ngafhi u wana dzilafho arali vho vha vhe na dali? Where would you go for treatment if you had malaria?

8. Zwi nga vha dzhiela tshifhinga tshingafhani u toda dzilafho nga murahu ha u vha na tsumbadwadze dza dali? How long after experiencing symptoms of malaria would you seek treatment?

9. Vhone kana munwe muthu mutani wavho o no vhuya a vha na dali? Ndi nnyi? Lini? Lungana? Have you or anyone else in your household had malaria? Who? When? How many times?

10. Vha pfa vho guda zwingafhani nga ha dali nga kha MAP? (1= Zwitukutuku, $\mathbf{5}=\mathbf{Z}$ winzhi) How much do you feel you learned about malaria through MAP (1=Very little, 5=A lot)

$\begin{array}{lllll}1 & 2 & 3 & 4 & 5\end{array}$

11. Vho difhelwa nga MAP zwingafhani? ( $1=$ Zwitukutuku, $\mathbf{5}=$ Nga maanda $)$ How much did you enjoy MAP (1=Very little, 5=A lot)

$\begin{array}{lllll}1 & 2 & 3 & 4 & 5\end{array}$


12. Hu na khonadzeo nngafhani ya uri vha themendele MAP kha khonani yavho? (1 = Zwi nga si konadzee, $\mathbf{5}$ = Zwi a konadzea nga maanda) How likely would you be to suggest MAP to a friend? (1=Very unlikely, 5=Very likely)

$\begin{array}{lllll}1 & 2 & 3 & 4 & 5\end{array}$

13. Vha nga kona u dovha vha vhuya hafhu sa mudzheneleli kha MAP ṅwakani? ( $1=$ Zwi nga si konadzee, $\mathbf{5}$ = Zwi a konadzea nga maanda) How likely would you be to return as a participant in the MAP again next winter? (1=Very unlikely, 5=Very likely)

$\begin{array}{lllll}1 & 2 & 3 & 4 & 5\end{array}$

14. Kuhumbulele kwavho kwa nga ha dali kwo shanduka hani nga murahu ha mitangano iyi? How has your view of malaria changed after these meetings?

15. Ndi zwifhio zwa ndemesa zwe vha zwi guda kha MAP? What is the most important thing you learned during MAP?

16. Vha humbula uri hu na zwinwevho zwine ra nga zwi ita u khwinisa "malaria awareness program" naa? Do you have any suggestions to improve the Malaria Awareness Program?

17. Huna zwinwevho zwine vha tama ri tshi zwi divha?(Mmbudziso kana vhudipfi havho?) Is there anything else you would like us to know? Questions? Comments? 
Figure 4a. Knowledge Score Classification of Participant Responses to Transmission Questions

TRANSMISSION: How/why do you think someone gets malaria?

Mention of mosquitos, mosquito bites

\section{METHODS DEEMED "CORRECT":}

Understanding of mosquito parasite

Understanding of mosquito laying eggs in water

View of standing, dirty, or river water

Dirty things attract mosquitos

Not using preventative measures that minimize mosquito bites (peaceful sleep cream, nets, sprayed house, or...)

\section{METHODS DEEMED “INCORRECT":}

Drinking contaminated, dirty, unpurified, or river water

Using dirty water

Eating sweet things

If mosquito bites animal and then you, you get malaria

Eating fruits that are not ripe; eating bad food

Drink beer while not eating food

If your body is use to getting sick, you are more likely to get malaria; the flu

Not having good hygiene (not washing hands before eating, or after using the toilet)

No mention of mosquitos, mosquito bites

Drinking Dirty Water

River water

Eating food that isn't covered

Unrelated (answering another question)

I don't know

Flies

Dirty house

Eating sweet food (fruit, watermelon, sugarcane)

Eating food that people are allergic to

Eating bad food; dirty food

By parasites that come from infected people/infected people

Not using preventative measures (wearing long clothes)

Poor Hygiene

\section{Knowledge Score Categorizations:}

0. Incorrect understanding of malaria transmission= No mention of mosquitos (no understanding or all incorrect)

1. Partially Correct understanding of malaria transmission= Mentions mosquitos \& methods deemed "incorrect" (General understanding of mosquitos, but not malaria as a whole)

2. Correct understanding of malaria transmission= Mention of mosquitos \& no methods deemed "incorrect" 
Figure 4b. Knowledge Score Classification of Participant Responses to Prevention Questions

PREVENTION: What do you think you/your community can do to prevent yourself from getting malaria?

METHODS DEEMED "CORRECT":

Fill holes/throw away trash/dirty things/empty tins (relation to rainwater and mosquitos)

Stay away from/get rid of still water (relation to mosquitos)

Mosquito nets, bed nets

Peaceful sleep cream

Mosquito coils

Allow Malaria Control people spray homes

Throw away cow dung (in relation to mosquitos)

Do not clean walls, house after Malaria Control sprays

Wear long clothes at dusk and/or sunset; cover-up exposed body to prevent mosquito bites

Education (from experts and others)

Get preventative mosquito repellants from clinic

Keep house clean, cut grass and bushes (relation to mosquitos)

Close windows

Stay inside during sunrise and sunset

Put oil in standing water to prevent mosquitos from breeding

Cut holes in tires

METHODS DEEMED "INCORRECT":

Don't know

Throw out trash/ keep house clean (not in relation to rainwater or mosquitos)

Traditional methods (burn cow dung/musudzungwane tree)

Go to the clinic or get medication/pills from clinic/call EMS

Don't keep food out for too long; Eat clean and healthy food

Do not spill water

Use Indian Tonic instead of water

Use/drink clean water (put jik in or boil dirty water before use)

Do not play in dirty/river water (no relation to mosquitos)

Incorrect understanding of how to use correct measures

Don't eat sweet food/unripe food

Force yourself to throw up, don't eat sour pap, avoid food with fats

Have good hygiene (wash hands before eating, or after using the toilet; bathing in hot water)

Drinking a lot of water

Knowledge Score Categorizations:

0. Incorrect understanding of malaria prevention (no understanding, all incorrect methods)

1. Partially Correct understanding of malaria prevention (some correct prevention techniques, some incorrect) 
2. Correct understanding of malaria prevention (all correct methods) 